\title{
Investigation of Collision Behavior of Hoisting Catenaries during a Lifting Cycle in Coal Mines
}

\author{
Jiannan Yao ${ }^{1,2}$ and Xingming Xiao ${ }^{1,2}$ \\ ${ }^{1}$ School of Mechanical and Electrical Engineering, China University of Mining \& Technology, Xuzhou 221116, China \\ ${ }^{2}$ Jiangsu Key Laboratory of Mine Mechanical and Electrical Equipment, China University of Mining \& Technology, \\ Xuzhou 221116, China \\ Correspondence should be addressed to Xingming Xiao; xxm_cumt@126.com
}

Received 4 February 2015; Revised 4 September 2015; Accepted 7 September 2015

Academic Editor: Domenico Mundo

Copyright (C) 2015 J. Yao and X. Xiao. This is an open access article distributed under the Creative Commons Attribution License, which permits unrestricted use, distribution, and reproduction in any medium, provided the original work is properly cited.

\begin{abstract}
This investigation focused on the analyses of transverse vibrations of mine hoisting catenaries where collision between adjacent ropes is more likely to occur. To support the analyses of transverse vibrations of catenaries, theoretical correlation models for longitudinal tension and transverse vibration were first established. Based on a severe rope collision case, on-site measurements and numerical simulations were performed. The research results indicated that the external second-order excitation frequency induced by axial fluctuations of head sheave was the primary excitation frequency, which was closer to the resonance frequency. Furthermore, the effects of excitation amplitude and imbalanced tension were also investigated revealing that larger excitation amplitude contributes to larger response amplitude and the maximum response amplitude of a catenary is sensitive to imbalanced rope tension. Eventually, new solutions, which will facilitate hoisting catenary operation beyond the resonance frequency range, were proposed.
\end{abstract}

\section{Introduction}

Steel wire ropes are widely used in many industrial applications due to their high axial strength and bending flexibility [1]. In this latter application, cables connecting the mine hoist and the hoisting conveyance have played a vital role in mine hoisting systems because their endurance strength and fatigue life have great effect on the mine production and safety of miners [2]. A mine multirope hoisting system is shown in Figure 1. It comprises a driving friction pulley, four hoisting ropes, two sets of head sheaves, two skips, and three tail ropes. The four hoisting ropes pass from the same friction pulley over the four singular head sheaves, forming four upper and lower catenaries, to the skip constrained to move in a vertical shaft, forming four vertical ropes hanging below the four singular head sheaves.

The difference of material property results in the difference of rope tension, which aggravates the friction of sheave groove [3]. To keep a balance of rope tension, a tension equilibrator is used to connect multiple ropes to hoisting conveyance as shown in Figure 2. The four main hoisting ropes are fixed to the piston poles while the hoisting conveyance is fixed to the cylinder blocks. Under the condition that one rope's tension is higher than the others, the oil of high pressure in the corresponding hydraulic cylinder will be squeezed into the other three hydraulic cylinders through a connection pipe, which leads to a new balance of the four rope tensions. However, due to the failure of tension equilibrator, such as the existence of creeping phenomenon between the cylinder blocks and the piston poles, the tensions in the four hoisting ropes are not completely equal.

During mine production, the hoisting ropes are always subjected to axial tensile loads and periodic external excitations resulting from axial fluctuations of friction pulley and head heaves, leading to transverse vibrations of the hoisting ropes. In vertical hoisting ropes, the transverse vibrations are mainly at the upper level of the shaft and usually of small amplitude. But in catenaries, the transverse vibrations are usually intense [4]. The resonance may make two adjacent catenaries collide with each other as shown in Figure 3, accelerating the rupture of the rope. Therefore, it is of great 


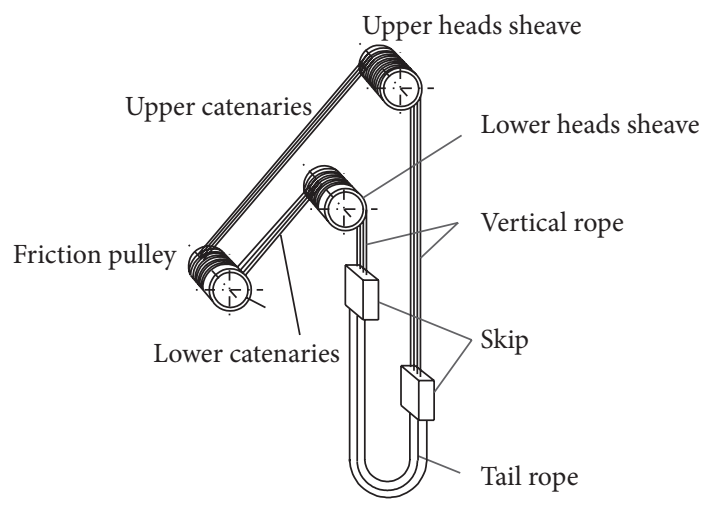

FIGURE 1: Schematic of a floor type multirope friction hoist in coal mine.

significance to explore the mechanism of the large amplitude transverse vibrations and propose reasonable solutions to reduce the transverse amplitude.

The previous researches on the dynamics of hoisting ropes in coal mines have been undertaken by some scholars. Kaczmarczyk and Ostachowicz $[4,5]$ derived a distributedparameter mathematical model by employing the classical moving coordinate frame approach and Hamilton's principle with no regard to the transverse motions of head sheave in a single-rope mine drum hoist. Kaczmarczyk [6] has also formulated an integral longitudinal model of the catenaryvertical hoisting cable system with a periodic excitation to analyze the passage through resonance. Wang et al. [7] investigated the lateral response of the moving hoisting conveyance in cable-guided hoisting systems and revealed that the maximum lateral displacement is linearly proportional to the excitation amplitude. Cao et al. $[8,9]$ established the coupled extensional-torsional model for a frictional hoisting system with an oriented pulley and the extensional-torsionallateral model for a winding hoisting system with a head heave. Mankowski and Cox [10] have studied the longitudinal response of mine hoisting cable to a kinetic shock load. Goroshko [11] described the longitudinal-torsional vibrations of ropes, the elongation of which is obtained during untwisting and the twisting moment occurring under tension.

From the literature reviews regarding the dynamics of hoisting ropes in coal mines, few literatures have dealt with the problem of large amplitude transverse vibrations of hoisting catenaries induced by axial fluctuations of head sheaves in a multirope friction hoist in colliery. The engineering significance of the present paper is to explore the mechanism of the collision behavior of the catenaries in coal mines and then propose reasonable solutions to realize resonance avoidance. Firstly, dynamic analyses of longitudinal rope tensions were investigated. Secondly, a theoretical model of transverse vibrations of hoisting catenaries was established. Finally, based on on-site measurements of a severe rope collision case, the mechanism of large amplitude transverse vibrations of catenaries was explored, providing theoretical basis for avoiding resonance.

\section{Dynamic Analyses of Longitudinal Tension}

2.1. Theory of Longitudinal Tension. The transverse vibrations of catenaries are associated with rope tension [3]. To provide a reliable basis for the analysis of collision behavior of hoisting catenaries, dynamic analyses of longitudinal tension were conducted. Figure 4 shows the working principle diagram of a hoisting rope in coal mines. The steel wire rope as a flexible body always subjects to dynamic load during the hoisting process. Based on the conclusion that the transverse vibrations in a vertical rope are of small amplitude [4], lateral oscillations are thereby not considered in the analysis of longitudinal tension. Considering that the effect of gravity due to a catenary inclination is small compared to the total quasi-static tension, the axial tensile loads along the catenary are assumed to be equal. The continuity of deflection across the head sheave requires that the dynamic tension in the catenary equals to that at the top of the vertical rope [5]. Hence, to obtain the dynamic tension in the catenary, it is imperative to explore the dynamic tension of the vertical rope.

The established coordinate system is located at the outer surface point of the sheave tangent to the vertical rope as shown in Figure 4. The elastic force instantaneously located in spatial position $x$ at time $t$ is represented by $S(t)$, which can be formulated from viscoelastic mechanics [12] as

$$
S(x, t)=E A(1+\mu) \frac{\partial u(x, t)}{\partial x},
$$

where $E A$ and $\mu$ are the axial rigidity and viscous damping coefficient of the hoisting rope, respectively, and $u(x, t)$ denotes the longitudinal dynamic displacement located in spatial position $x$ at time $t$. According to the force condition of the infinitesimal length $d x$ as shown in Figure 4, the dynamic governing equation of the vertical rope can be formulated as

$$
\begin{aligned}
& S(x, t)-\left[S(x, t)+\frac{\partial S(x, t)}{\partial x} d x\right]-\rho d x \frac{\partial^{2} u(x, t)}{\partial t^{2}} \\
& \quad=\rho d x a(t),
\end{aligned}
$$

where $\rho$ is the linear density of the rope and $a(t)$ denotes the hosting acceleration with respect to hoisting time $t$. Substituting (1) into (2) yields

$$
\frac{\partial^{2} u(x, t)}{\partial t^{2}}+E A \rho^{-1}(1+\mu) \frac{\partial^{2} u(x, t)}{\partial x^{2}}=-a(t) .
$$

The boundary conditions of (3) can be expressed as

$$
\begin{aligned}
& u(x, t)=0, \quad x=0 \\
& E A\left(1+\mu \frac{\partial}{\partial t}\right) \frac{\partial u(x, t)}{\partial x}-\frac{Q(x, t)}{g} \frac{\partial^{2} u(x, t)}{\partial t^{2}} \\
& =\frac{Q(x, t)}{g} a(t), \quad x=l(t),
\end{aligned}
$$

where $Q(x, t)$ denotes the quasi-static tension instantaneously located in spatial position $x$ at time $t$. During 


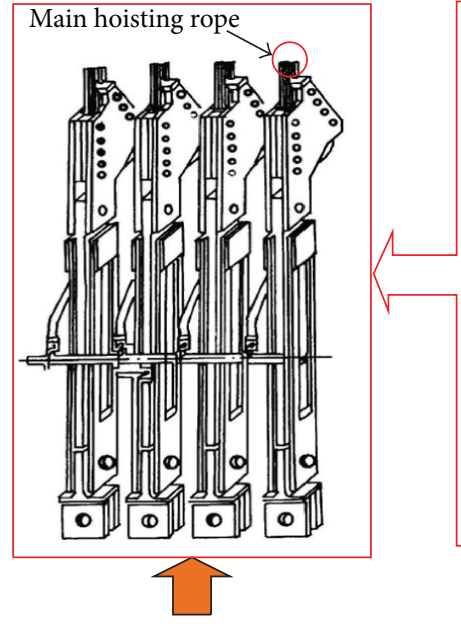

Tension equilibrator

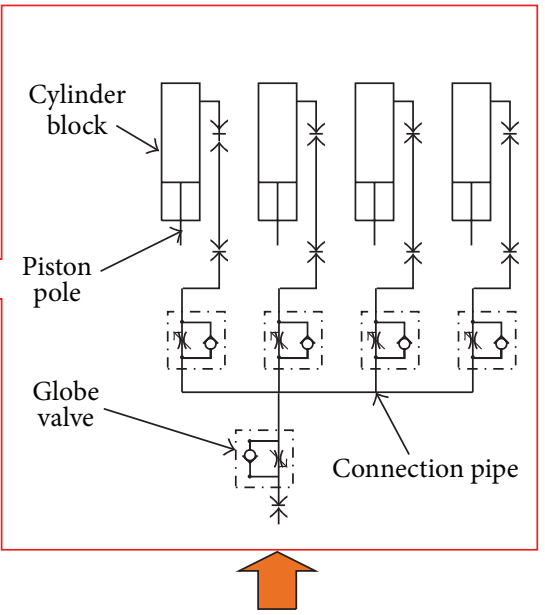

Working principle diagram

FIGURE 2: Diagram of a tension equilibrator and its working principle.

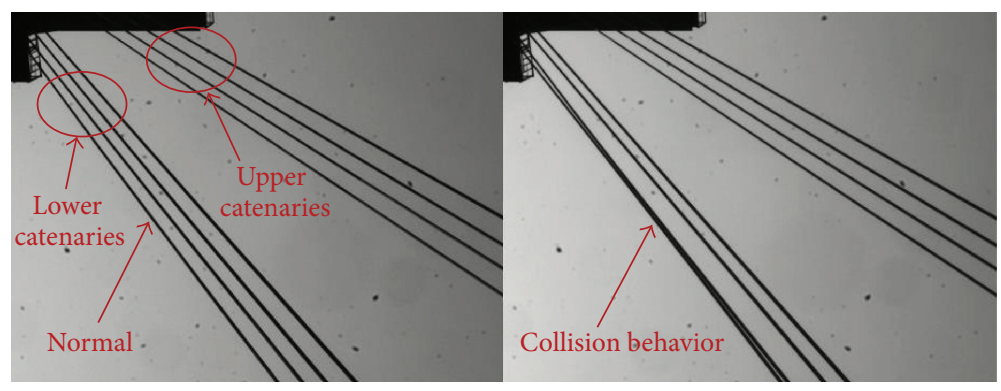

FIgURE 3: Diagram of collision behavior of hoisting catenaries.

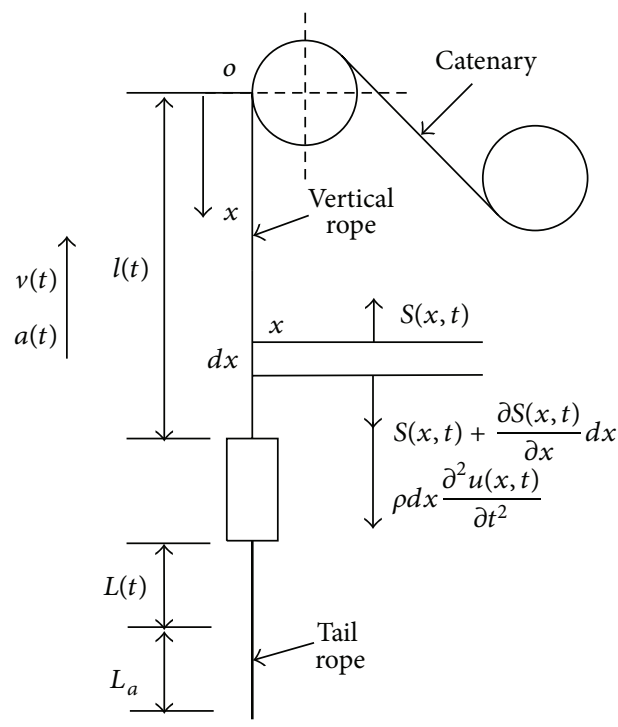

FIGURE 4: Working principle diagram of hoisting rope in coalmine.

the lifting cycles, the mass of the main hoisting rope and tail rope is time-varying. And the time-varying mass of tail rope was integrated into the mass of hoisting conveyance.
Therefore, the dynamic tension in a vertical rope during the lifting process is formulated as

$$
\begin{aligned}
& Q(x, t) \\
& \quad=\sigma_{i}\left\{m_{e}+m_{p}+3 \rho_{w}\left[L(t)+L_{a}\right]+\rho[l(t)-x]\right\} \\
& \cdot[g+a(t)],
\end{aligned}
$$

where the parameter $m_{e}$ represents the mass of the skip and the additional device, $m_{p}$ and $\rho_{w}$ correspond to the payload and the linear density of a hoisting tail rope, $L(t)$ is the distance that the skip has covered until time $t, L_{a}$ denotes the minimum length of a hoisting tail rope during lifting, and $g$ is the acceleration of gravity. Due to the failure of tension equilibrator, such as the existence of creeping phenomenon between cylinder blocks and piston poles, the tensions in the four hoisting ropes are not completely equal. Therefore, an imbalance coefficient $\sigma_{i}$ is introduced

$$
\sum_{i=1}^{4} \frac{\sigma_{i}}{4}=1
$$

where $i$ represents the $i$ th rope. If the tensions in the four hoisting ropes are equal, $\sigma_{1}=\sigma_{2}=\sigma_{3}=\sigma_{4}=1$.

The solutions of the inhomogeneous equation (3) contain a general solution and a particular solution. To solve 
an inhomogeneous equation, its general solution is generally solved ahead of its particular solution. First, after having transformed (3) into a homogeneous equation and assumed the dynamic displacement $u(t)=X(x) \times T(t)$, by employing the method of separation of variables and using the boundary conditions in (4), the Eigen function of the vibration of the steel wire rope can be calculated as [13]

$$
\begin{aligned}
X_{m}(x, t) & =\sin \frac{\lambda_{m}(t)}{l(t)} x \quad(m=1,2,3, \ldots) \\
\lambda \tan \lambda & =\frac{\rho l(t) g}{Q(l(t), t)},
\end{aligned}
$$

where $\lambda_{m}(t)$ denotes the $m$ th approximate solution of transcendental equation (8).

Subsequently, to solve the inhomogeneous equation (3) using the generalized coordinate method, assume that

$$
u(x, t)=\sum_{m=1}^{\infty} X_{m}(x, t) q_{m}(t)
$$

where $q_{m}(t)$ is the generalized coordinate with respect to time only. The Lagrange equation of the system can be written as

$$
\begin{gathered}
\frac{d}{d t} \frac{\partial K}{\partial\left(\partial q_{m}(t) / \partial t\right)}-\frac{\partial K}{\partial q_{m}(t)}+\frac{\partial R}{\partial\left(\partial q_{m}(t) / \partial t\right)}+\frac{\partial V}{\partial q_{m}(t)}=Q_{m}(t) \\
K=\frac{\rho}{2} \sum_{m=1}^{\infty}\left(\frac{\partial q_{m}}{\partial t}\right)^{2} \int_{0}^{l(t)} X_{m}^{2}(x, t) d x+\frac{Q}{g}\left(\frac{\partial q_{m}}{\partial t}\right)^{2} X_{m}^{2}(l(t), t) \\
V=\frac{E A}{2} \sum_{m=1}^{\infty} q_{m}^{2}(t) \int_{0}^{l(t)}\left(\frac{\partial X_{m}(x, t)}{\partial x}\right)^{2} d x \\
R=\frac{\mu E A}{2} \sum_{m=1}^{\infty}\left(\frac{\partial q_{m}}{\partial t}\right)^{2} \int_{0}^{l(t)}\left(\frac{\partial X_{m}(x, t)}{\partial x}\right)^{2} d x
\end{gathered}
$$

where $K, V$, and $R$ represent the kinetic energy, potential energy, and dissipated energy of the system, respectively. Substituting (7), (11) into (10) yields

$$
\begin{gathered}
\frac{\partial^{2} q_{m}(t)}{\partial t^{2}}+\mu \frac{E A \lambda_{m}^{2}(t)}{\rho l^{2}(t)} \frac{\partial q_{m}(t)}{\partial t}+\frac{E A \lambda_{m}^{2}(t)}{\rho l^{2}(t)} q_{m}(t) \\
=\frac{\lambda_{m}^{2}(t) Q_{m}(t)}{\rho l^{2}(t) \int_{0}^{l(t)}\left(\partial X_{m}(x, t) / \partial x\right)^{2} d x}
\end{gathered}
$$

Solving (12) yields

$$
\begin{aligned}
q_{m}(t)= & \frac{\lambda_{m}^{2}(t)}{\rho l^{2}(t) \int_{0}^{l(t)}\left(\partial X_{m}(x, t) / \partial x\right)^{2} d x} \frac{e^{-h_{m} t}}{w_{m}(t)} \\
& \cdot \int_{0}^{t} e^{h_{m} \tau} Q_{m}(\tau) \sin \omega_{m}(t-\tau) d \tau,
\end{aligned}
$$

where

$$
\begin{aligned}
Q_{m}(t) & =\frac{\rho l(t) a(t)}{\lambda_{m}(t)} \\
h_{m}(t) & =\sqrt{\frac{E A \lambda_{m}^{2}(t) \mu}{2 \rho l^{2}(t)}} \\
\omega_{m}(t) & =\sqrt{\frac{E A \lambda_{m}^{2}(t)}{\rho l^{2}(t)}\left(1-\frac{\mu}{2}\right)} .
\end{aligned}
$$

Therefore, the solution for the inhomogeneous equation (3) can be got as

$$
u(x, t)=\sum_{m=1}^{\infty} \sin \left(\frac{\lambda_{m}(t)}{l(t)} x\right) q_{m}(t)
$$

Due to $T(x, t)$, the dynamic tension instantaneously located in spatial position $x$ at time $t$; is the sum of the elastic force $S(t)$ and the quasi-static force $Q(x, t)$; therefore,

$$
\begin{aligned}
& T(x, t)=Q(x, t) a(t) g^{-1}\left\{\left[1+\alpha(t)-\alpha(t) x l^{-1}(t)\right]\right. \\
& -4 \alpha(t) \sum_{m=1}^{\infty}\left\{\left[\frac{\cos \left(\lambda_{m}(t) x / l(t)\right)}{\lambda_{m}^{2}(t)\left(2 \lambda_{m}(t)+\sin 2 \lambda_{m}(t)\right)}\right]\right. \\
& \left.\left.\cdot e^{-h_{m}(t) t}\left[\cos \omega_{m}(t) t-\frac{h_{m}(t)}{\omega_{m}(t)} \sin \omega_{m}(t) t\right]\right\}\right\} \\
& +Q(x, t),
\end{aligned}
$$

where

$$
\alpha(t)=\frac{\rho l(t) g}{Q(l(t), t)} .
$$

2.2. Simulation Analyses. According to (16) in Section 2.1, the dynamic tensions in a vertical rope at the skip end and sheave end were calculated. Two typical working conditions (ascending with no payload and full payload) were taken into account. The upward movement profile, as shown in Figure 5, is divided into seven stages. The velocity function $v(t)$ is given by the following formula:

$$
v_{i}(t)=v_{0 i}+a_{i} \Delta t_{i}, \quad(i=1,2, \ldots, 7)
$$

where the initial velocities at the 1 st to 7 th stage, $v_{01}$ to $v_{07}$, are $0,0.59 \mathrm{~m} / \mathrm{s}, 9.31 \mathrm{~m} / \mathrm{s}, 9.31 \mathrm{~m} / \mathrm{s}, 1.76 \mathrm{~m} / \mathrm{s}, 1.76 \mathrm{~m} / \mathrm{s}$, and $0.72 \mathrm{~m} / \mathrm{s}$, respectively, the accelerations at the $1 \mathrm{st}$ to 7 th stage 


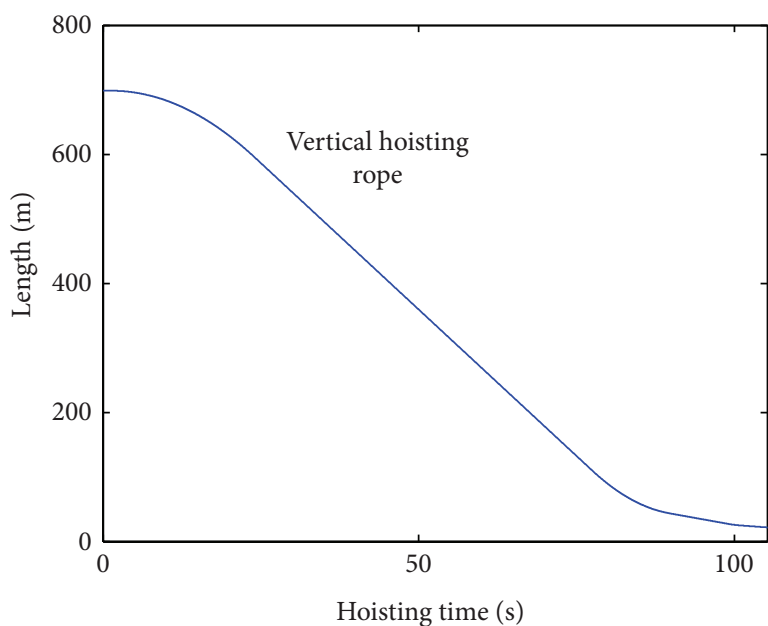

(a)

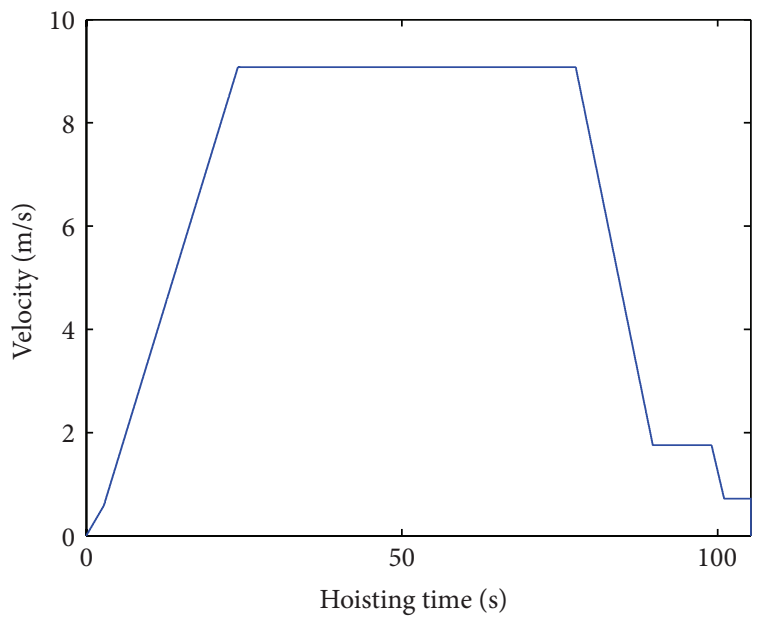

(c)

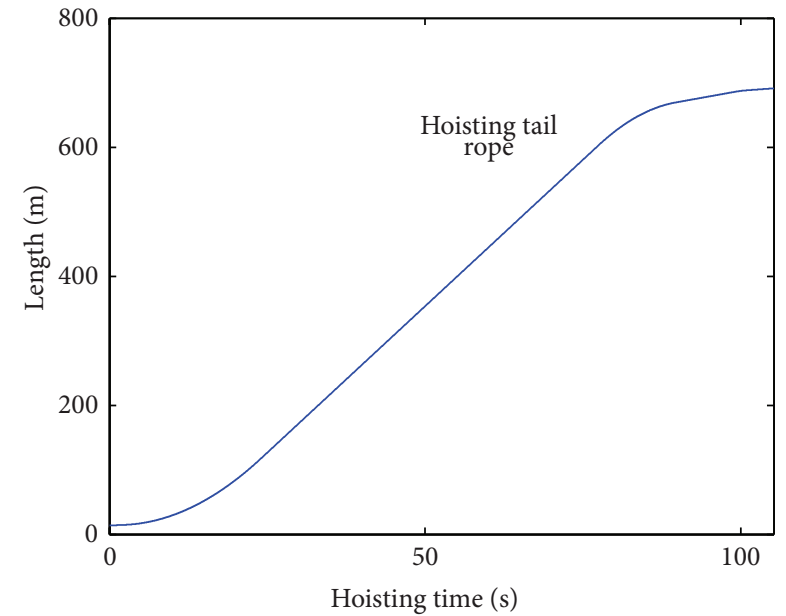

(b)

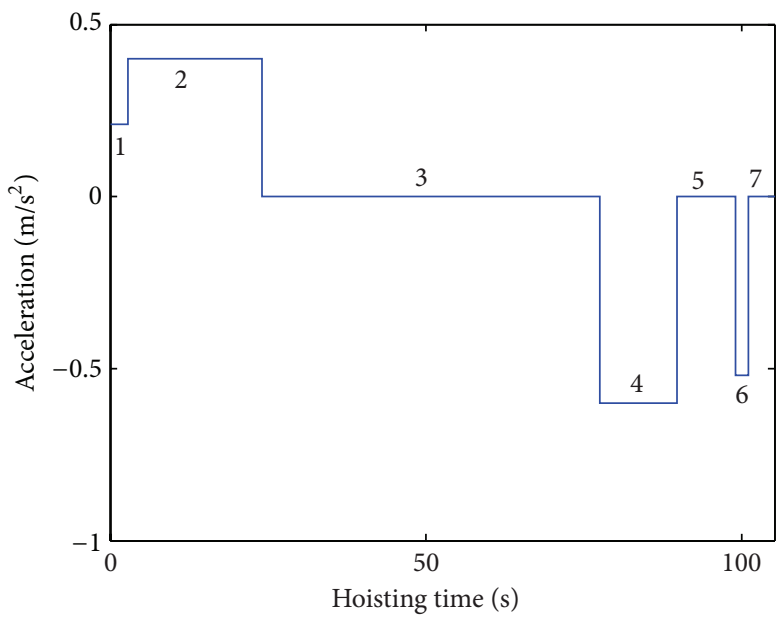

(d)

FiguRE 5: Upward movement profile of the skip: (a) time-varying length of the vertical hoisting rope; (b) time-varying length of the hoisting tail rope; (c) hosting velocity; (d) hoisting acceleration. The seven stages are marked in (d).

are $0.21 \mathrm{~m} / \mathrm{s}^{2}, 0.4 \mathrm{~m} / \mathrm{s}^{2}, 0,-0.6 \mathrm{~m} / \mathrm{s}^{2}, 0,-0.52 \mathrm{~m} / \mathrm{s}^{2}$, and 0 , respectively, and the hoisting time at the 1 st to 7 th stage are $2.8 \mathrm{~s}, 21.8 \mathrm{~s}, 53.5 \mathrm{~s}, 12.6 \mathrm{~s}, 9.3 \mathrm{~s}, 2 \mathrm{~s}$, and $4 \mathrm{~s}$ in sequence. According to the velocity function $v(t)$, the time-varying length of the vertical rope and that of the tail rope are shown in Figures 5(a) and 5(b). The hoisting parameters are shown in Table 1.

Figure 6 shows the simulation results of rope tensions at the skip end and the sheave end under the two typical working conditions. To obtain a theoretical balance value, the tension imbalance coefficient $\sigma_{i}(i=1,2,3,4)$ was set as 1 . The seven stages are marked in the red dashed line corresponding to those in Figure 5(d). It is obviously seen that the fluctuating rope tension occurs at the acceleration or deceleration hoisting stages, such as the first, second, fourth, and sixth hoisting stage as shown in Figure 6, and decreases with the hoisting time rapidly. During the constant speed hoisting stages (the third, fifth, and seventh hoisting stage shown in Figure 6), the variation of rope tension is stable without fluctuation. Sudden change of rope tension at transitional stages between adjacent lifting stages results from the internal load and the flexible impact due to the sudden change of acceleration. Under the two typical working conditions, the overall rise of rope tension at the skip end is attributed to the increasing hoisting tail rope length; meanwhile, the rope tension at the sheave end is basically constant during the constant speed hoisting stage.

Considering the conclusion mentioned in Section 2.1 that the dynamic tension in the catenary equals to that at the top of the vertical rope, the response curves at the sheave end in Figure 6 also represent the tensions in catenaries. In terms of industrial applications, during the maximum constant speed stage, the transverse vibrations of hoisting catenaries are most intense and collision between two adjacent catenaries is thereby more likely to occur. Hence, the tensions at the sheave end at the third hoisting stage are of interest and adopted to conduct the analysis of the transverse vibrations of hoisting catenaries. 
TABLE 1: Parameters of the hoisting system.

\begin{tabular}{lcc}
\hline Parameters of the hoisting system & Notation & Parameter value \\
\hline Rope spacing $(\mathrm{mm})$ & $L_{R}$ & 350 \\
Diameter of hoisting rope $(\mathrm{mm})$ & $d$ & 43 \\
Diameter of the head sheave $(\mathrm{m})$ & $D$ & 4.5 \\
Maximum hoisting speed $(\mathrm{m} / \mathrm{s})$ & $v_{m}$ & 9.31 \\
Length of the lower inclined catenary $(\mathrm{m})$ & $L_{c}$ & 43.74 \\
Maximum length of vertical hoisting rope $(\mathrm{m})$ & $l_{\max }$ & 699 \\
Minimum length of hoisting tail rope $(\mathrm{m})$ & $L_{a}$ & 14 \\
Mass of full payload $(\mathrm{kg})$ & $m_{p}$ & 18000 \\
Mass of the skip and its additional devices $(\mathrm{kg})$ & $m_{e}$ & 17983 \\
Viscous damping coefficient & $\mu$ & 0.0056 \\
Young's modulus of the hoisting rope $(\mathrm{Pa})$ & $E$ & $1 \times 10^{11}$ \\
Cross-sectional area of the hoisting rope $\left(\mathrm{mm}{ }^{2}\right)$ & $A$ & 1452.2 \\
Mass of the hoisting rope per unit meter $(\mathrm{kg} / \mathrm{m})$ & $\rho$ & 7.86 \\
Mass of the hoisting tail rope per unit $\mathrm{meter}(\mathrm{kg} / \mathrm{m})$ & $\rho_{w}$ & 10.48 \\
\hline
\end{tabular}

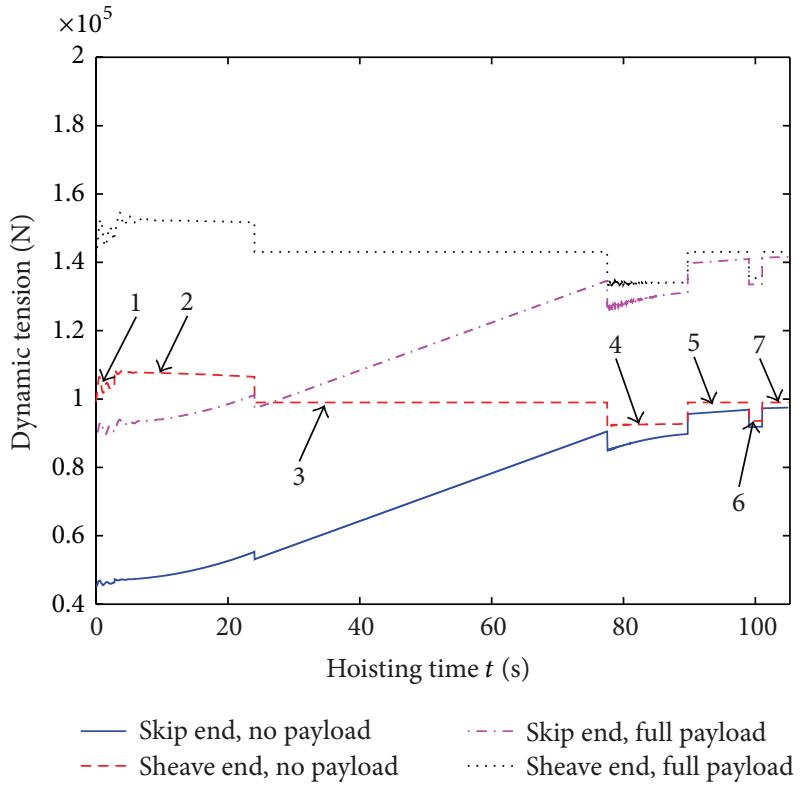

Figure 6: Dynamic tension at the skip end and sheave end during hoisting process.

\section{Theoretical Model of Transverse Vibration}

To describe the transverse vibrations of hoisting catenaries, a fixed coordinate system $o x y$ is established. Considering that the effect of gravity due to a catenary inclination is small compared to the total quasi-static tension, the hoisting catenaries can be viewed as four horizontally moving catenaries with constant length $L$ in the $x-y$ plane as shown in Figure 7 [4]. The four catenaries wrap around the same friction pulley and attach to the four singular sheaves, respectively. Therefore, the friction pulley is modeled as a fixed-center pulley with axial fluctuating displacement specified by $e_{0}(t)$, and the four singular head sheaves are modelled as four particles subjected to axial fluctuating displacement specified by $e_{1}(t), e_{2}(t)$,

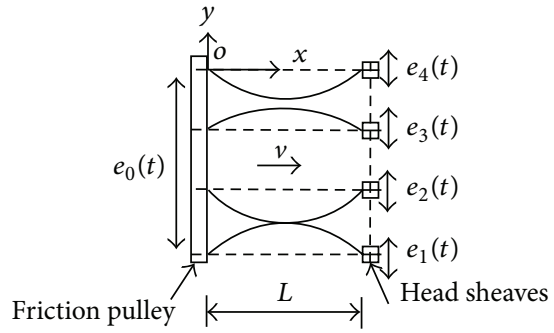

FIgURE 7: Diagram of the transverse vibration model of hoisting catenaries.

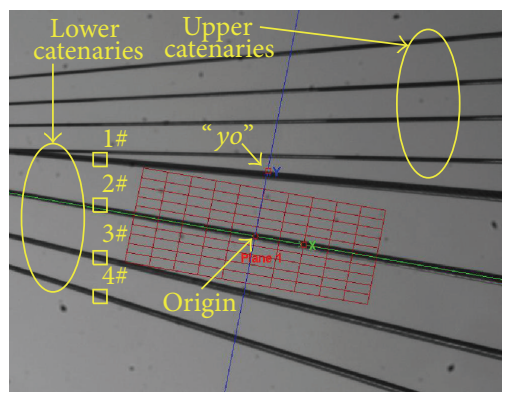

Figure 8: Processed image of the transverse vibration displacements.

$e_{3}(t)$, and $e_{4}(t)$, respectively, where $t$ is the hoisting time. Due to the industrial fact that axial fluctuations of head sheaves excite the transverse vibrations of hoisting catenaries, the rope vibrations are predominantly along the $y$ direction in plane as shown in Figure 7. Therefore, regardless of spatial motions, the planar vibrations are of interest to explore the collision mechanism of the catenaries.

In the present study, considering that the transverse displacement of the catenary is very small compared to the catenary length, and the rope tension is sufficiently so large that its variation due to extension of the rope can be negligible. Therefore, a linear model can be introduced to 


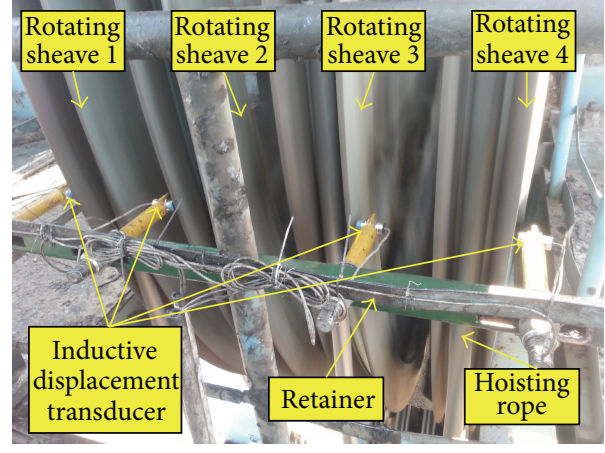

Figure 9: Measurement of the axial fluctuating displacements of head sheaves.

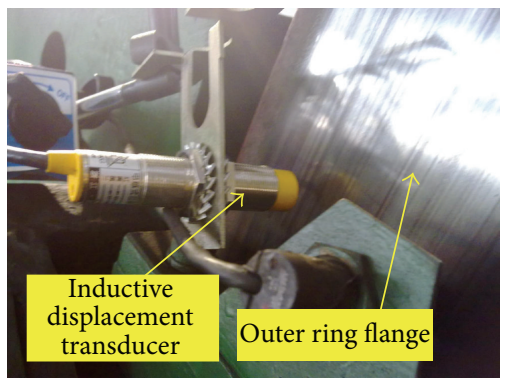

FIgURE 10: Measurement of the axial fluctuating displacements of friction pulley.

describe the lateral oscillation of the catenary in coal mine [14-16]:

$$
\begin{aligned}
\rho\left(y_{t t}+a(t) y_{x}+2 v(t) y_{x t}+v^{2}(t) y_{x x}\right)= & T y_{x x}, \\
& 0 \leq x \leq L,
\end{aligned}
$$

where $y(x, t)$ is the transverse displacement of the rope particle instantaneously located in spatial position $x$ at time $t$ and the subscripts $x$ and $t$ denote partial differentiation, $\rho$ and $L$ are the linear density and length of the hoisting catenary, $a(t)$ and $v(t)$ are the hoisting acceleration and velocity, respectively, and $T$ is the constant tension in the catenary at the constant maximum hoisting speed stage (the third hoisting stage in Figure 6). The nonhomogeneous boundary conditions resulting from axial fluctuations of friction pulley and head sheaves are defined by

$$
\begin{aligned}
& y(0, t)=e_{0}(t), \\
& y(L, t)=e_{i}(t) \quad(i=1,2,3,4),
\end{aligned}
$$

where $i$ represents the $i$ th catenary as shown in Figure 7. Using the method from literature [17], the transverse displacement can be expressed as

$$
\begin{aligned}
& y(x, t)=u(x, t)+h(x, t) \\
& h(x, t)=e_{0}(t)+\frac{\left[e_{i}(t)-e_{0}(t)\right] x}{L},
\end{aligned}
$$

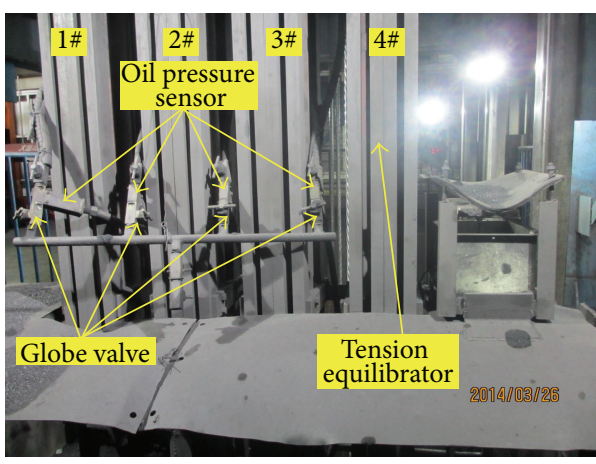

FIGURE 11: Measurement of the oil pressure of the tension equilibrator.

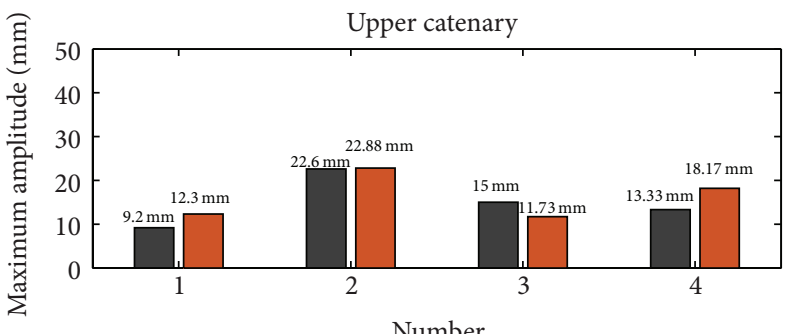

Full payload

$\square$ No payload
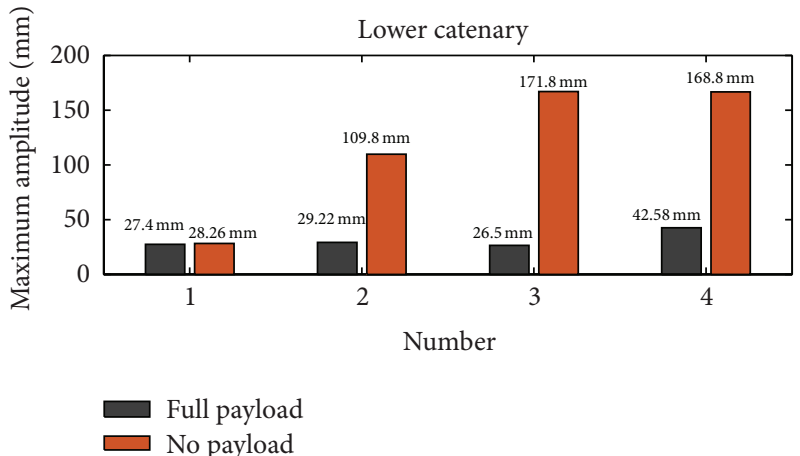

FIGURE 12: Maximum transverse amplitudes of the catenaries.

where $u(x, t)$ is the part that satisfies the homogeneous boundary conditions and $h(x, t)$ is the nonhomogeneous part. Substituting (21) into (19) yields

$$
\begin{aligned}
& \rho\left(u_{t t}+a(t) u_{x}+2 v(t) u_{x t}+v^{2}(t) u_{x x}\right)-T u_{x x} \\
& =f(x, t), \quad 0<x<L \\
& f(x, t) \\
& =-\rho\left[h_{t t}+a(t) h_{x}+2 v(t) h_{x t}+v^{2}(t) h_{x x}\right] \\
& \quad+T h_{x x},
\end{aligned}
$$

where $f(x, t)$ is the additional forcing term induced by transforming the governing equation with time dependent 

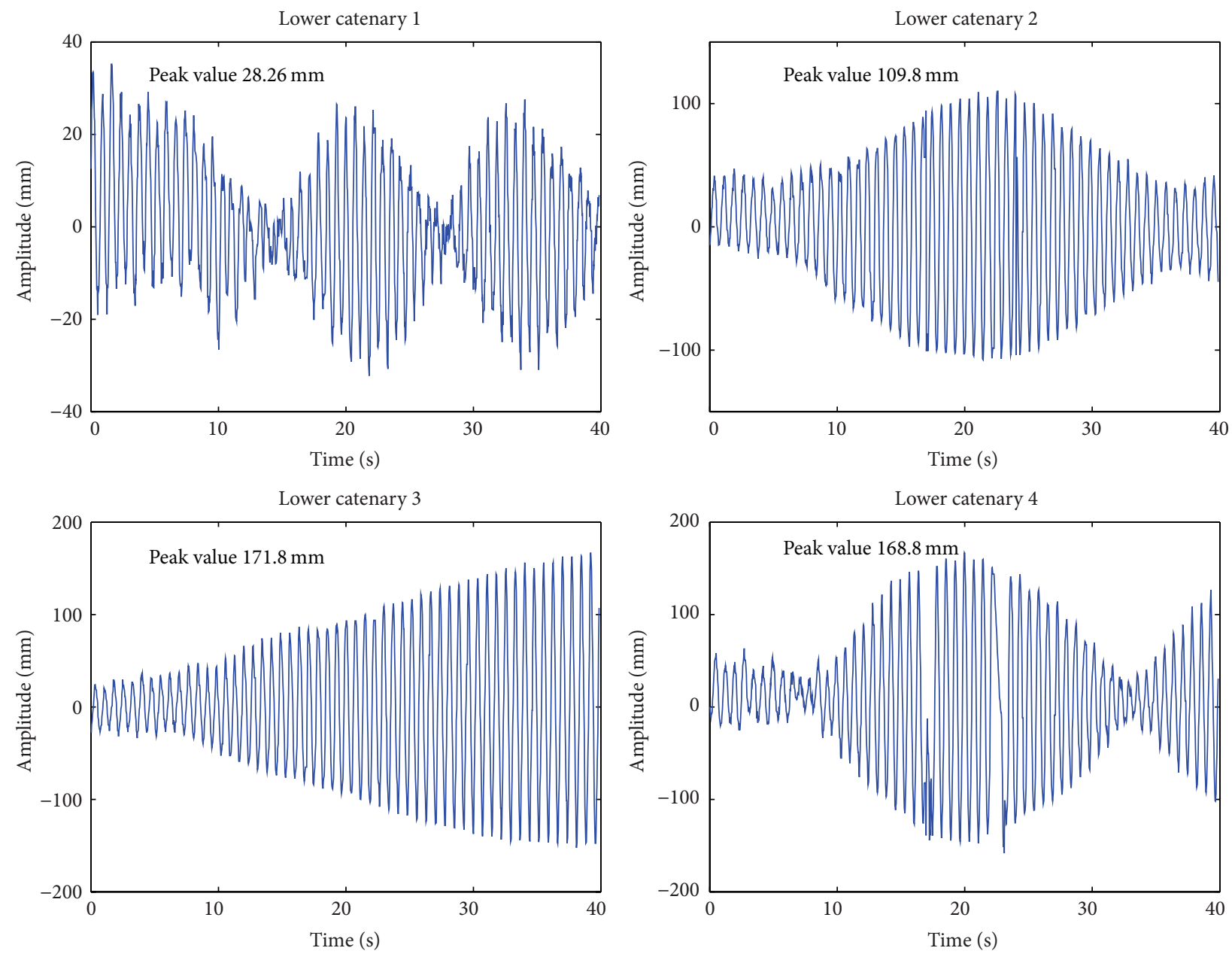

FIGURE 13: Transverse vibrations at the center of lower catenaries with no payload.

nonhomogeneous boundary conditions to one with homogeneous boundary conditions. Applying Galerkin method, assume that the solution of infinite number of degrees of freedom for (19) can be formulated in the following form [18]:

$$
\begin{aligned}
u(x, t) & =\sum_{i=1}^{n} q_{i}(t) \varphi_{i}(\xi) \\
\varphi_{i}(\xi) & =\sin (i \pi \xi) \\
\xi & =\frac{x}{L}
\end{aligned}
$$

where $\varphi_{i}(\xi)$ is the trial function, $q_{i}(t)$ is the generalized coordinate, and $n$ is the number of included modes. Substituting (22) and (24) into (23), then multiplying (23) by $\varphi_{j}(\xi)(j=$ $1,2, \ldots, n)$, and integrating (23) over the interval of 0 and 1 , the ordinary differential equations can be obtained as

$$
M \ddot{Q}+C \dot{Q}+K Q=F,
$$

where $Q=\left[q_{1}(t), q_{2}(t), \ldots, q_{n}(t)\right]^{T}$, and the elements of the entries in (25) are defined as

$$
\begin{aligned}
& m_{i j}= \begin{cases}0.5, & \text { if } i=j \\
0, & \text { if } i \neq j\end{cases} \\
& c_{i j}= \begin{cases}0, & \text { if } i+j \text { is even } \\
4 i j v(t) L^{-1}\left(j^{2}-i^{2}\right)^{-1}, & \text { if } i+j \text { is odd }\end{cases} \\
& k_{i j}= \begin{cases}0.5\left(i \pi L^{-1}\right)^{2}\left[T \rho^{-1}-v^{2}(t)\right], & \text { if } i=j \\
2 i j a(t) L^{-1}\left(j^{2}-i^{2}\right)^{-1}, & \text { if } i \neq j, i+j \text { is odd } \\
0, & \text { if } i \neq j, i+j \text { is even }\end{cases} \\
& f_{i}=-\int_{0}^{1}\left\{\ddot{e}_{0}(t)+a(t) L^{-1}\left[e_{i}(t)-e_{0}(t)\right]\right. \\
& \left.+2 v(t) L^{-1}\left(\dot{e}_{i}-\dot{e}_{0}\right)+\left(\ddot{e}_{i}-\ddot{e}_{0}\right) \xi\right\} \varphi_{j}(\xi) d \xi,
\end{aligned}
$$

where the superscript denotes differentiation with respect to time. For linear vibrations, the 4-term Galerkin truncation is of enough precise [19]; therefore, the included number of 

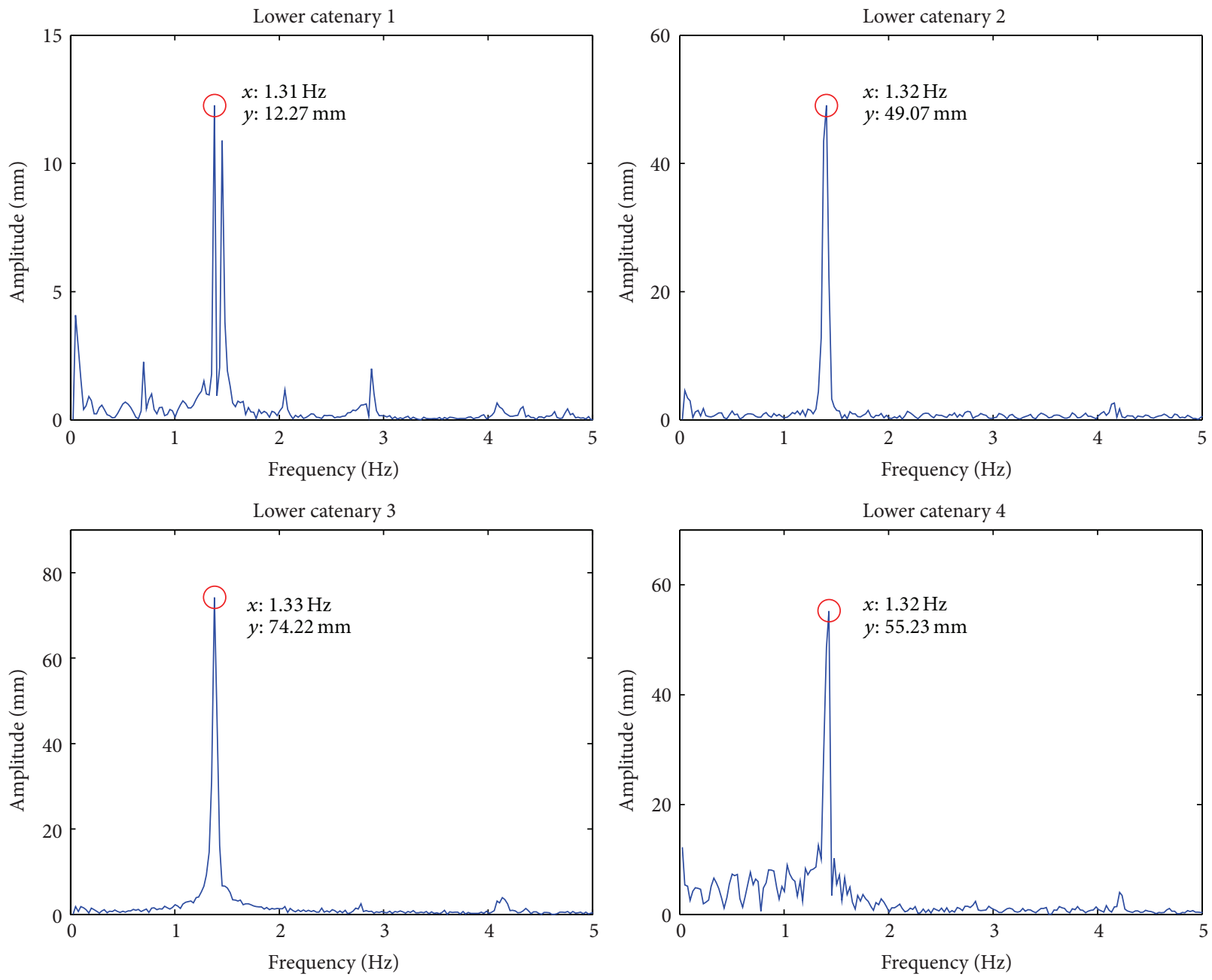

FIgURE 14: Amplitude spectrums corresponding to lower catenaries.

modes are determined as 4 in this case. For the established model in Figure 7 the solution for $u(x, t)$ is sought first; subsequently $y(x, t)$ is obtained by applying (21) and (22).

\section{Case Study}

4.1. On-Site Measurements. Real object tests were performed on a multirope friction hoist with four hoisting catenaries. A noncontact video gauge whose capacity ranges from $1 \mathrm{~mm}$ to $100 \mathrm{~m}$ was placed beneath the moving catenaries at an arbitrary appropriate distance. A red grid overlaying the image is the coordinate frame to define the measuring scale of vibration displacements as shown in Figure 8. The $x$-axis is parallel to the longitudinal direction of the catenaries while $y$-axis is parallel to the lateral. The scaling factor to the pixel measurements is calculated by two points over a known distance from the origin of the coordinate frame to the point marked with " $y o$ " along the $y$-axis, and the distance between the two points is the rope spacing of $350 \mathrm{~mm}$ in this case. With these coordinates for the geometry measurements, the transverse vibration displacements of the hoisting catenaries can be recorded and then analyzed.
During the measurement of transverse displacements of catenaries, the axial fluctuating displacements of the four singular head sheaves and the friction pulley were recorded. Four inductive displacement transducers fixed in the retainer were adjusted to face the outer rim of the four sheaves numbered as 1\# to 4\# shown in Figure 9. Additionally, using the same method an inductive displacement transducer was employed to record the axial fluctuating displacements of the friction pulley during the hoisting process as shown in Figure 10.

At the same time, measurement of the tension at the end of a vertical hoisting rope was made by measuring the oil pressure of the tension equilibrator. To identify the exact test value of the tension of a singular hoisting rope, the four globe valves were closed before the test as shown in Figure 11.

4.2. The Analysis of the Transverse Vibrations of Catenaries. The measured maximum transverse amplitudes at the center of the catenaries numbered as $1 \#$ to $4 \#$ (Figure 8) during the constant speed stage are demonstrated in Figure 12. It can be seen that there is no obvious difference between the upper catenaries while significant difference occurs in 

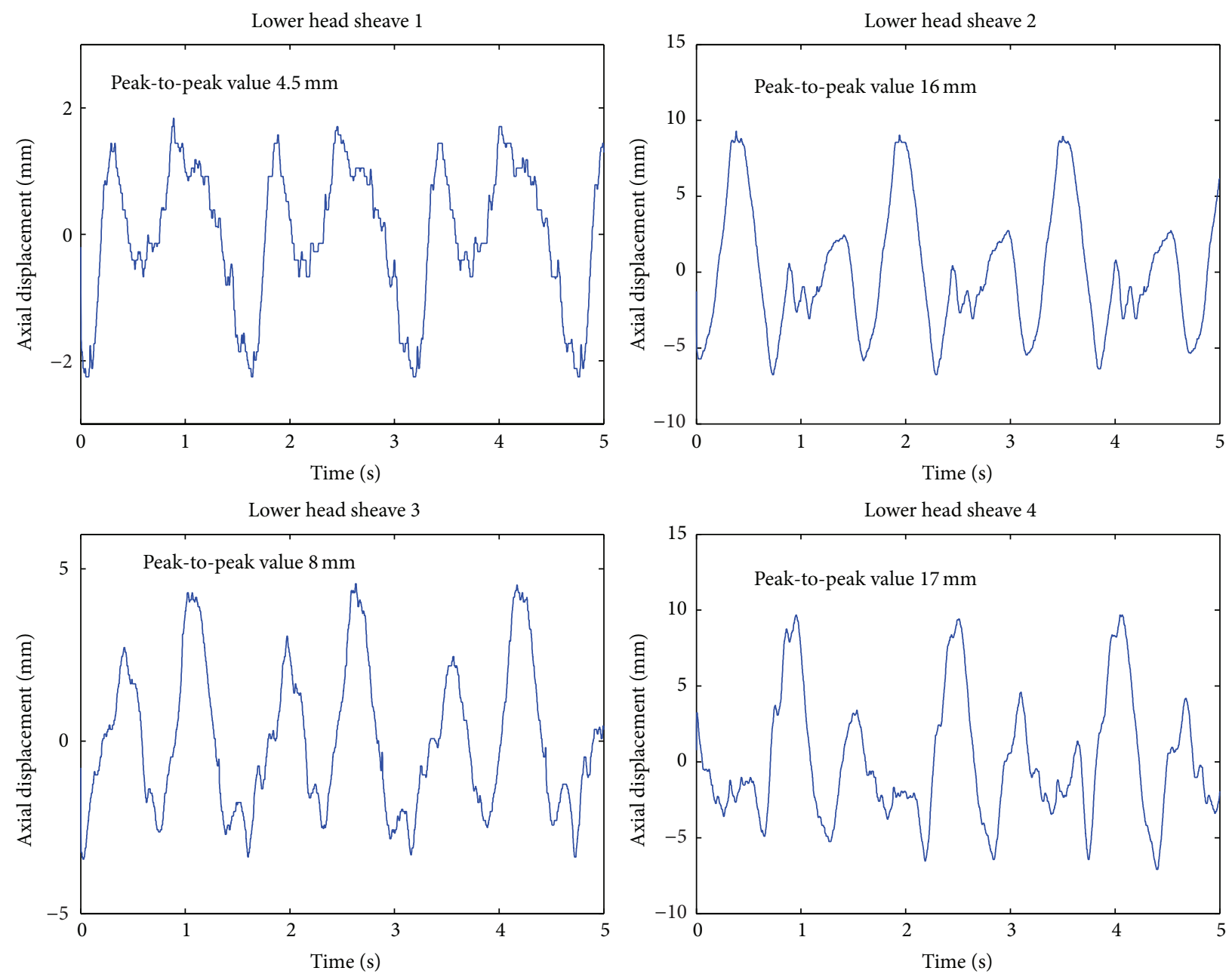

Figure 15: Partial fluctuating waveforms of axial fluctuations of head sheaves.

the lower catenaries. Especially at the center of the lower catenary $2 \#$ catenary to $4 \#$, the maximum amplitudes under the condition of no load are much larger than those with full payload. The rope spacing among the four catenaries is $350 \mathrm{~mm}$; therefore, if the maximum transverse amplitudes of two adjacent catenaries both exceed the dangerous threshold of $175 \mathrm{~mm}$, collision will be resulted in and the rupture of the rope is thereby accelerated. Hence, the situations at the center of the lower catenary 3\# and catenary 4\# shown in Figure 12 can be identified as a fault state because they are much close to the dangerous threshold.

To analyze the behavior of large transverse amplitude of catenaries, the transverse displacements during the constant speed stage at the center of the lower catenaries under the circumstance of no payload were given in Figure 13. Using fast Fourier transform (FFT), the corresponding amplitude spectrums were illustrated in Figure 14. It can be seen from Figure 13 that clear resonance occurred in lower catenary 2\# to catenary 4\#, and the main vibration frequencies are $1.31 \mathrm{~Hz}$, $1.32 \mathrm{~Hz}, 1.33 \mathrm{~Hz}$, and $1.32 \mathrm{~Hz}$ relating to lower catenary $1 \#$ to catenary $4 \#$, respectively.
4.3. The Analysis of External Displacement Excitations. The measured axial fluctuating displacements of lower head sheaves $1 \#$ to $4 \#$ at the constant speed stage are shown in Figure 15, and the corresponding amplitude spectrums are given in Figure 16. The catenaries share the same friction pulley, so they have the same axial fluctuating displacements as shown in Figure 17. The peak-to-peak values of the axial fluctuations of lower head sheaves 1 \# to $4 \#$ are $4.5 \mathrm{~mm}, 16 \mathrm{~mm}$, $8 \mathrm{~mm}$, and $17 \mathrm{~mm}$, respectively. The rotational frequency of the head sheave is $f=v_{m} / \pi D=0.66 \mathrm{~Hz}$, which also acts as the fundamental excitation frequency of the external excitations. And it can be inferred from Figures 16 and 17 that the first three-order frequency components play the dominating roles in the external displacement excitations. Furthermore, the first three-order excitation amplitudes in the friction pulley are approximately zero which are far less than those in the head sheaves; thus, they can be ignored in this case.

4.4. The Analysis of the Tensions of Catenaries. The tension of a catenary cannot be measured directly while it can be 

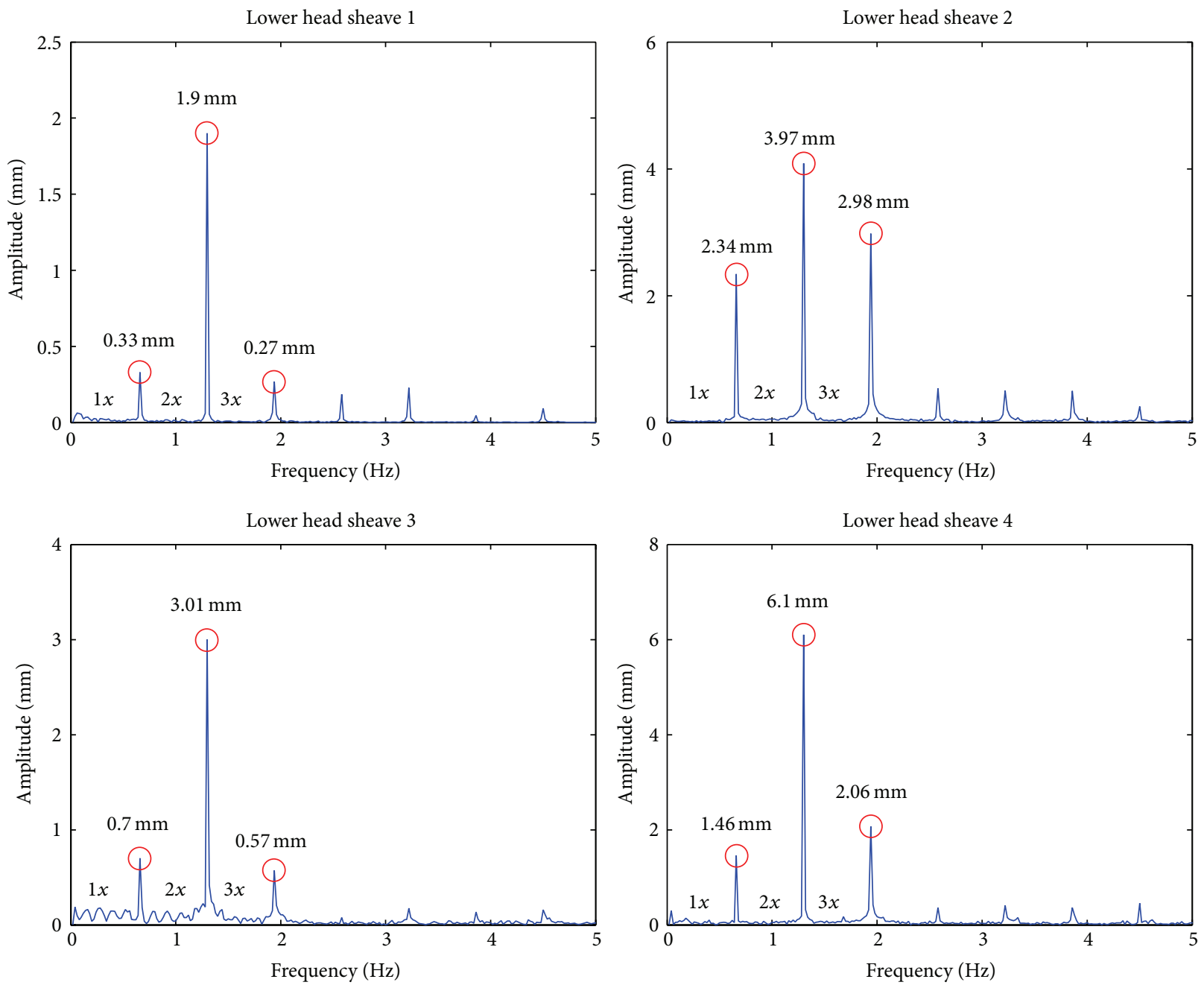

FIGURE 16: Amplitude spectrums corresponding to axial fluctuations of head sheaves.

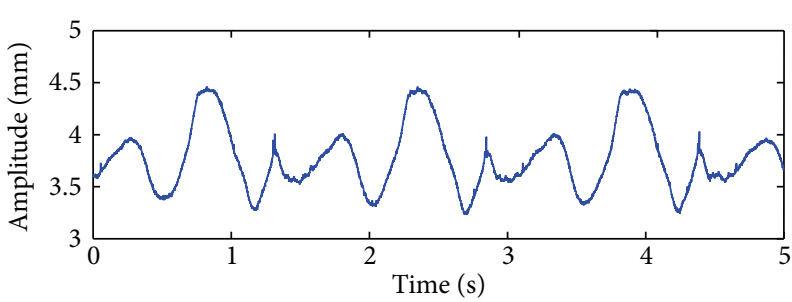

(a)

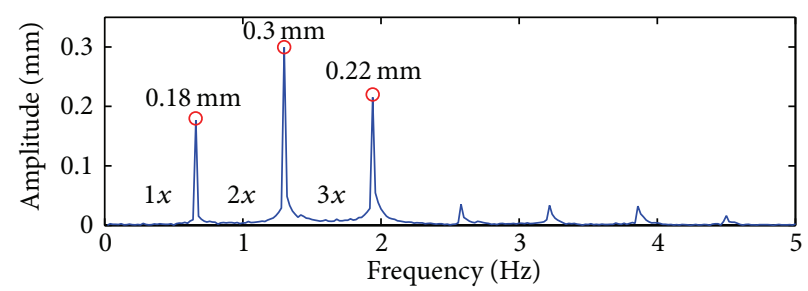

(b)

FIGURE 17: Measured data of axial fluctuations of friction pulley.

predicted by calculating (16). In this case, the tension at the skip end can be obtained by measuring the oil pressure of the tension equilibrator. After linear transformation and median filtering, the tension-time curves during the upward movement were presented as curve 2 in Figure 18. Curves 1 and 3 are the theoretical balance curves relating to sheave end and skip end which are calculated by substituting the practical parameters listed in Table 1 into (16). According to the conclusion mentioned in Section 2.1 that the dynamic tension in the catenary equals that at the vertical rope top end, therefore, curve 1 shown in Figure 18 also represents the theoretical balance tension of a catenary. It can be concluded from Figure 18 that the tensions in the four catenaries are exactly unbalanced. Through the comparison of curves 2 and 3 , the unbalance coefficients for the tensions in lower catenary 1\# to catenary $4 \#$ referred to as $\sigma_{1}, \sigma_{2}, \sigma_{3}$, and $\sigma_{4}$ can be determined as $0.95,1.01,1.03$, and 1.01 .

4.5. Simulation and Validation. In Section 4.3, it has been concluded that the first three-order frequency components 

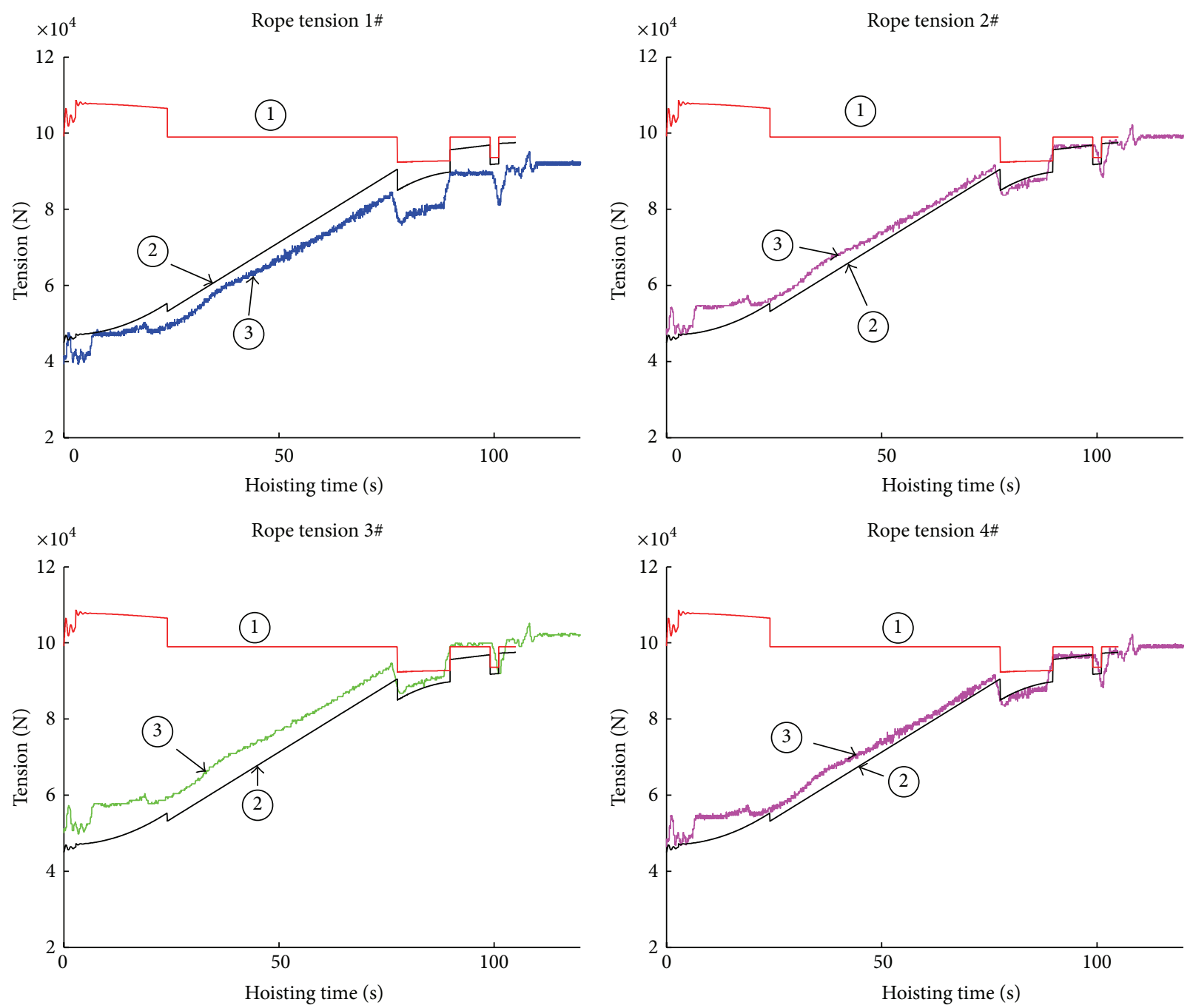

FIGURE 18: Contrast of theoretical and practical rope tensions.

play the dominating roles in the external displacement excitations and thus can be specified by $A_{1} \sin (w t), A_{2} \sin (2 w t)$, and $A_{3} \sin (3 w t)$, where $A_{1}, A_{2}$, and $A_{3}$ are the first threeorder harmonic amplitudes which can be determined from Figure 16, $w$ is the angular velocity of the head sheave. The maximum constant hoisting speed in this case is $v_{m}=$ $9.31 \mathrm{~m} / \mathrm{s}$; then the angular velocity during the constant speed stage can be calculated as $4.14 \mathrm{rad} / \mathrm{s}$ from the formula $w=$ $2 v_{m} / D$, where $D$ is the diameter of head sheave valuing $4.5 \mathrm{~m}$. According to Figure 6, under the circumstance of no payload, the theoretical balance tension in a catenary during the constant speed stage is $99990 \mathrm{~N}$. Additionally, the unbalance coefficients for the tensions in lower catenary $1 \#$ to catenary $4 \#$ referred to as $\sigma_{1}, \sigma_{2}, \sigma_{3}$, and $\sigma_{4}$ are $0.95,1.01$, 1.03 , and 1.01, respectively. Therefore, the exact tensions in the lower catenary $1 \#$ to catenary 4 \# can be derived as $94990 \mathrm{~N}$, $100990 \mathrm{~N}, 103000 \mathrm{~N}$, and $100990 \mathrm{~N}$. Using the practical hoisting parameters and substituting the exact rope tensions and the first three-order excitations shown in Figure 16 into (25) and (26), the response amplitudes at the center of the four catenaries in time domain are demonstrated in Figures 1922. It can be seen that the first- and third-order response amplitudes are much smaller than the second-order and thereby can be negligible. The simulation maximum secondorder response amplitudes at the center of the lower catenary $1 \#$ to catenary $4 \#$ are $22.34 \mathrm{~mm}, 104.3 \mathrm{~mm}, 172.2 \mathrm{~mm}$, and $160.2 \mathrm{~mm}$, respectively, which are much close to the measured $28.26 \mathrm{~mm}, 109.8 \mathrm{~mm}, 171.8 \mathrm{~mm}$, and $168.8 \mathrm{~mm}$ as shown in Figure 13. The difference may result from model errors, which are acceptable when the primary purpose is fault diagnosis. Furthermore, the shapes of the vibrating waveforms under the second-order excitations in Figures 19-22 are much similar to the measured as shown in Figure 13. Therefore, the validity and applicability of the established linear transverse vibration model can be confirmed. What is more, the main vibration frequencies of the measured data in lower catenary 1\# to catenary $4 \#$ are $1.31 \mathrm{~Hz}, 1.32 \mathrm{~Hz}, 1.33 \mathrm{~Hz}$, and $1.32 \mathrm{~Hz}$, which are approximately double the rotational frequency; hence, it can be concluded that the second-order harmonic frequency is the primary excitation frequency in this case. 


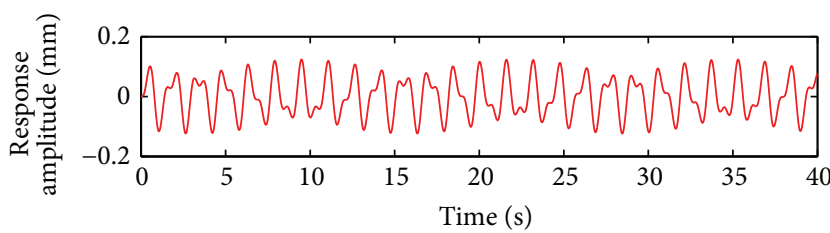

(a) Excitation: $0.33 \sin (4.14 t)$

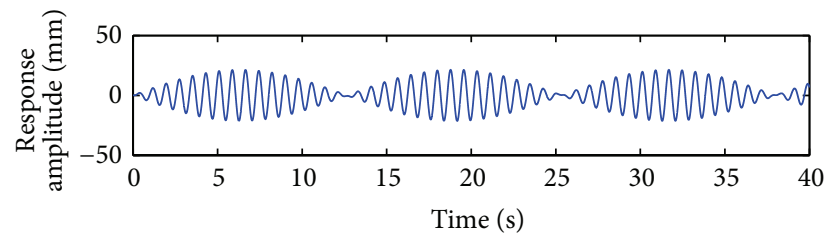

(b) Excitation: $1.9 \sin (8.28 t)$

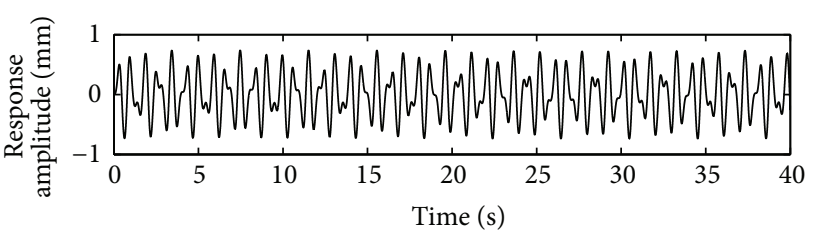

(c) Excitation: $0.27 \sin (12.42 t)$

FIGURE 19: Simulation of transverse vibrations in lower catenary 1.

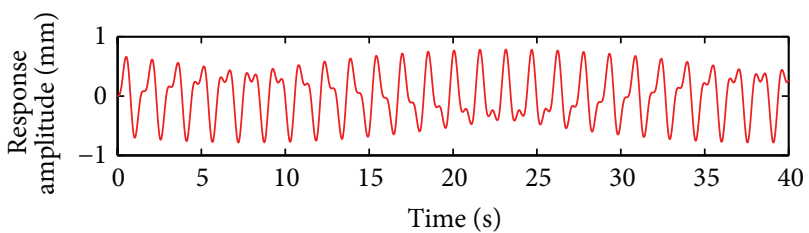

(a) Excitation: $2.34 \sin (4.14 t)$

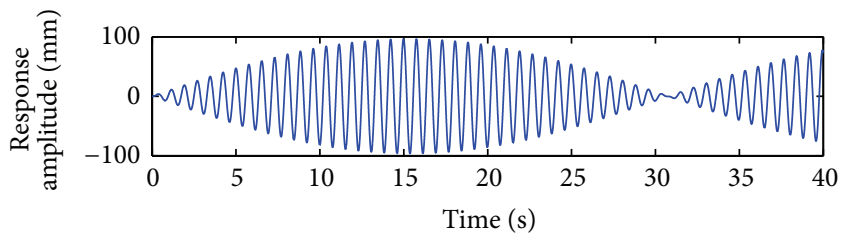

(b) Excitation: $3.97 \sin (8.28 t)$

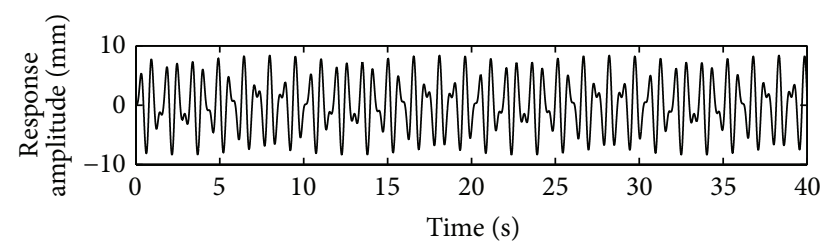

(c) Excitation: $2.98 \sin (12.42 t)$

FIGURE 20: Simulation of transverse vibrations in lower catenary 2.

4.6. Fault Analysis. To account for the large transverse amplitudes studied in this case, the maximum response amplitudes in the four lower catenaries with varying excitation frequencies are plotted in Figure 23. Considering the conclusion given in Section 4.5 that the second-order harmonic frequency is the primary excitation frequency, the excitation amplitudes are thus chosen as $1.9 \mathrm{~mm}, 3.97 \mathrm{~mm}, 3.01 \mathrm{~mm}$,

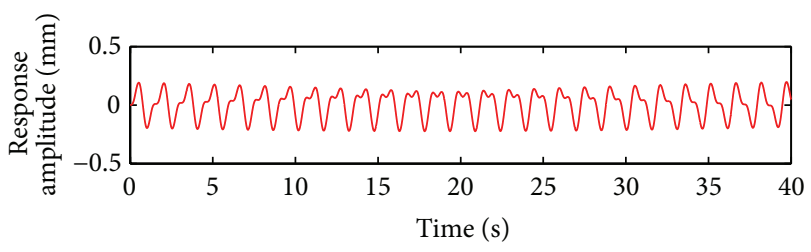

(a) Excitation: $0.7 \sin (4.14 t)$

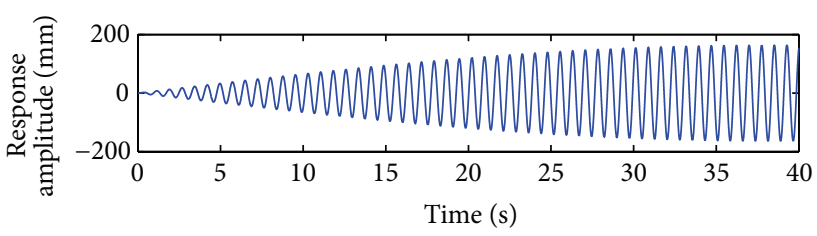

(b) Excitation: $3.01 \sin (8.28 t)$

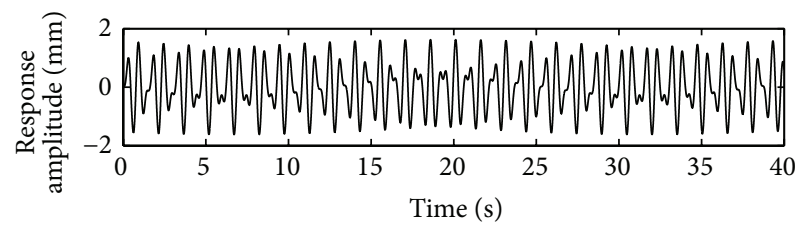

(c) Excitation: $0.57 \sin (12.42 t)$

Figure 21: Simulation of transverse vibrations in lower catenary 3.

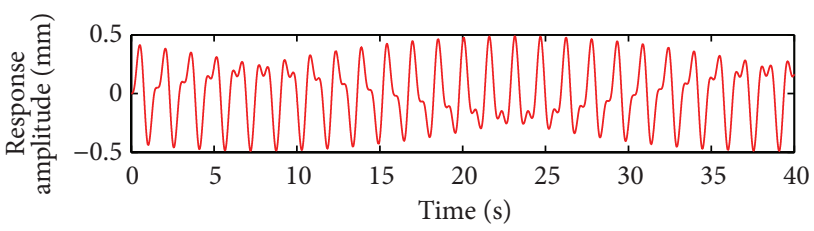

(a) Excitation: $1.46 \sin (4.14 t)$

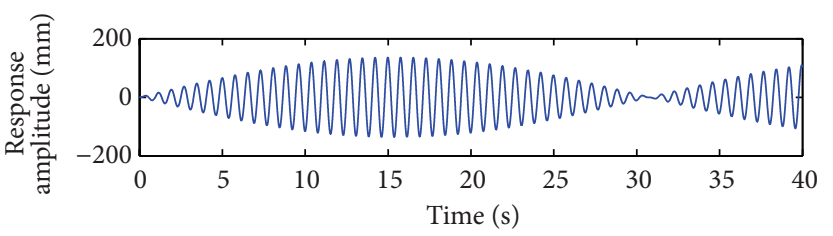

(b) Excitation: $6.1 \sin (8.28 t)$

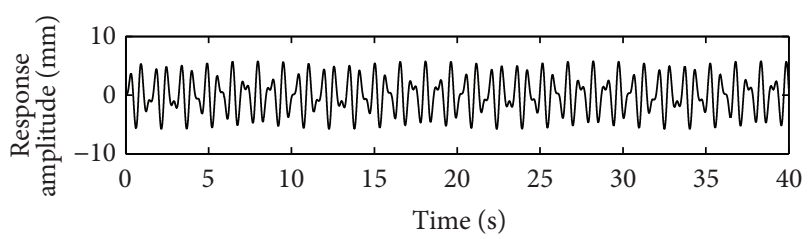

(c) Excitation: $2.06 \sin (12.42 t)$

FIGURE 22: Simulation of transverse vibrations in lower catenary 4.

and $6.1 \mathrm{~mm}$ as shown in Figure 22. And the rope tensions in Figures 23(a)-23(d) are 94990 N, 100990 N, 103000 N, and $100990 \mathrm{~N}$ relative to lower catenary $1 \#$ to catenary 4\#, which are the same as those in Section 4.5. The resonance points referred to as P1, P2, P3, and P4 in Figure 22 are $(7.79 \mathrm{rad} / \mathrm{s}$, $186.4 \mathrm{~mm}),(8.08 \mathrm{rad} / \mathrm{s}, 397.7 \mathrm{~mm}),(8.2 \mathrm{rad} / \mathrm{s}, 306.6 \mathrm{~mm})$, and $(8.08 \mathrm{rad} / \mathrm{s}, 611.1 \mathrm{~mm})$. It is obvious that the second-order 


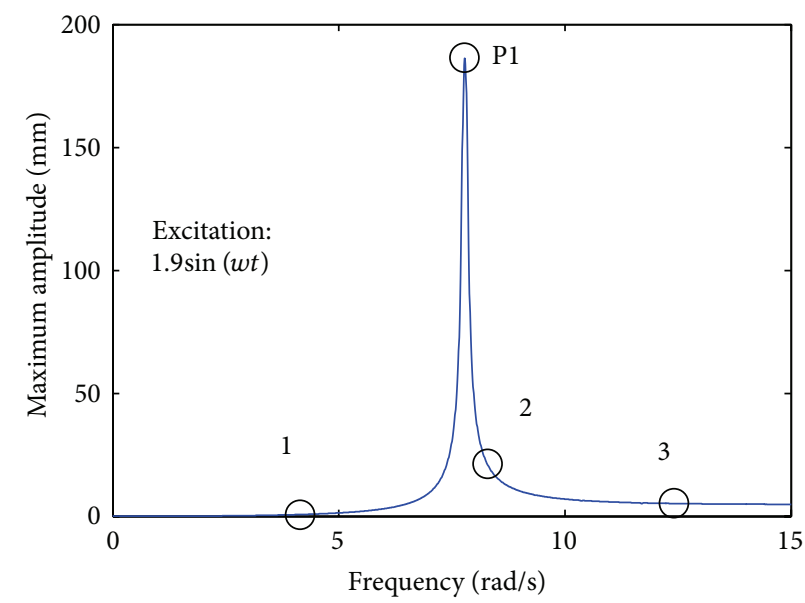

(a)

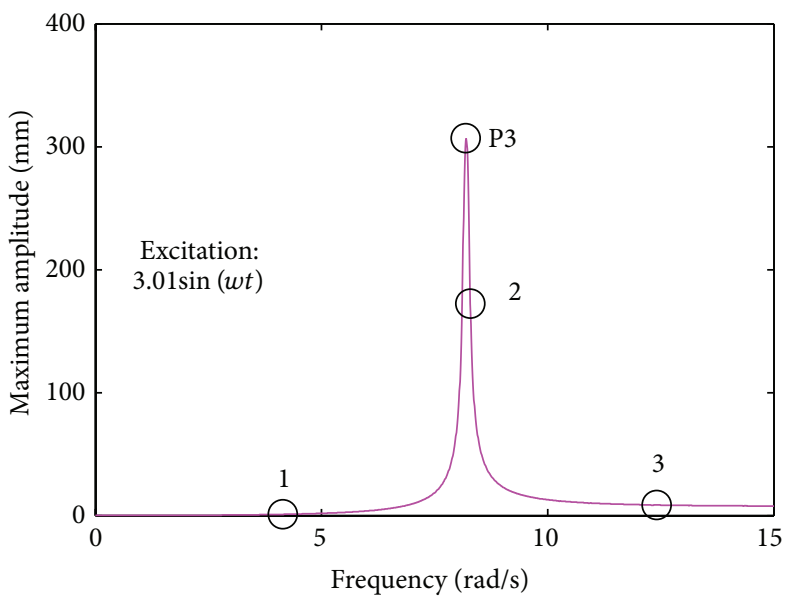

(c)

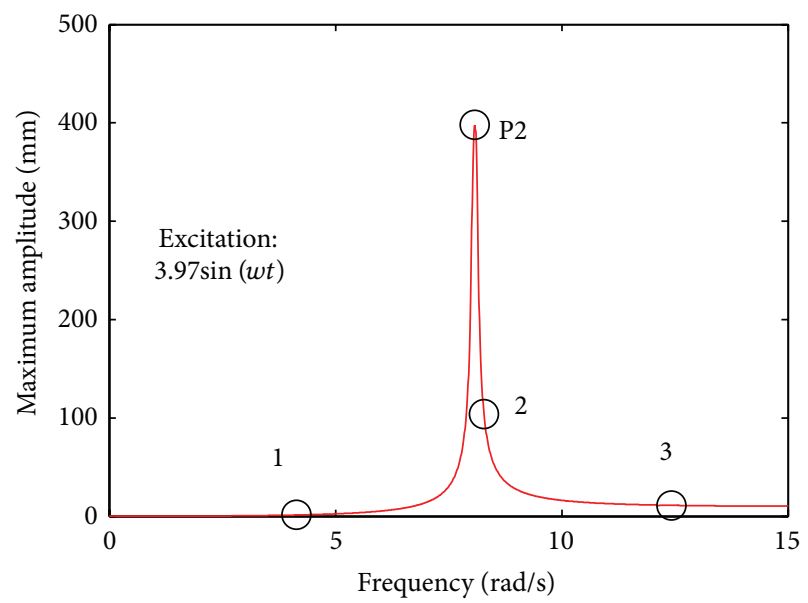

(b)

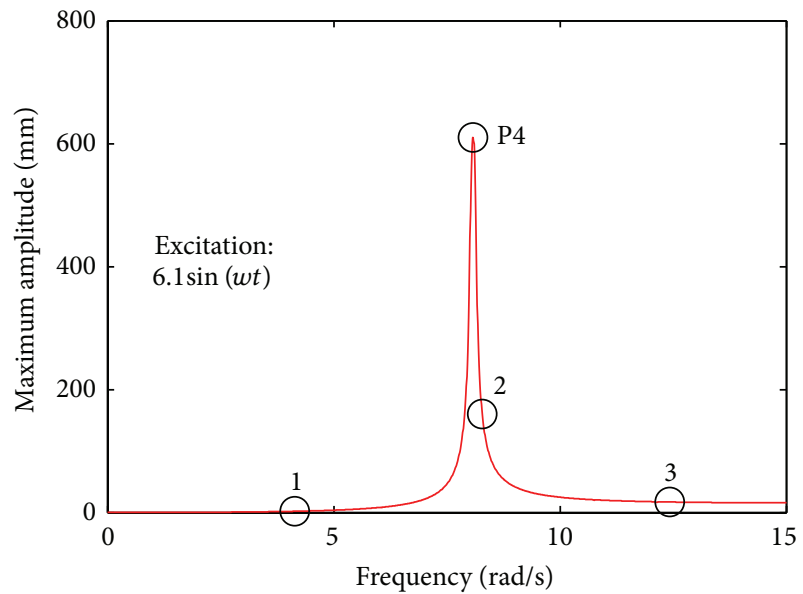

(d)

FIgURE 23: Amplitude-frequency curves of the transverse vibrations in catenaries.

excitation frequency of $8.28 \mathrm{rad} / \mathrm{s}$ is closer to the resonance frequency than the first- and third-order, accounting for the fact that the second-order amplitude is much larger than the first- and third-order.

Additionally, to explore the effect of unbalanced rope tensions on the transverse vibrations of catenaries, under the excitations of $A_{1} \sin (2 w t), A_{2} \sin (2 w t), A_{3} \sin (2 w t)$, and $A_{4} \sin (2 w t)$ where $A_{1}$ to $A_{4}$ are the second-order excitation amplitudes studied in this case, the response curves of maximum amplitudes are obtained by varying the imbalance coefficient of tension as shown in Figure 24. It can be inferred that larger excitation amplitude contributes to larger response amplitude. Above all, under the circumstance of unbalanced coefficient 1.05, the smallest response amplitude is even $245 \mathrm{~mm}$ with the minimum excitation amplitude $1.9 \mathrm{~mm}$. The rope spacing studied in this case is $350 \mathrm{~mm}$, so if two catenaries are suffering the same unbalanced coefficient 1.05 and the second-order excitation amplitudes are even the same minimum value of $1.9 \mathrm{~mm}$, the sum of the two maximum transverse amplitudes at the center of the catenaries will be $490 \mathrm{~mm}$ exceeding the rope spacing and the dangerous collision are absolutely caused.

\section{Summary and Conclusions}

The transverse vibrations in the hoisting catenaries where the collision is more likely to occur are particularly focused on in the present study. Theoretical correlation models for the longitudinal tension and transverse vibration were first established. The on-site measurements were performed indicating that the intense transverse vibrations are more likely to occur in the lower catenaries with no payload. Additionally, it was also found that the tensions in the four hoisting ropes are not completely equal in the practical use. To explore the mechanism of large transverse amplitude of a catenary, numerical simulations were performed on the basis of the measured data indicating that the second-order excitation frequency of the external excitations induced by the axial fluctuations of the head sheaves is the primary excitation frequency, which is closer to the resonance frequency range. Furthermore, the effects of excitation amplitude and the imbalanced tension of a catenary are also investigated revealing that larger excitation amplitude contributes to larger response amplitude; above all, the maximum response transverse amplitude is sensitive to the imbalanced rope tension. 


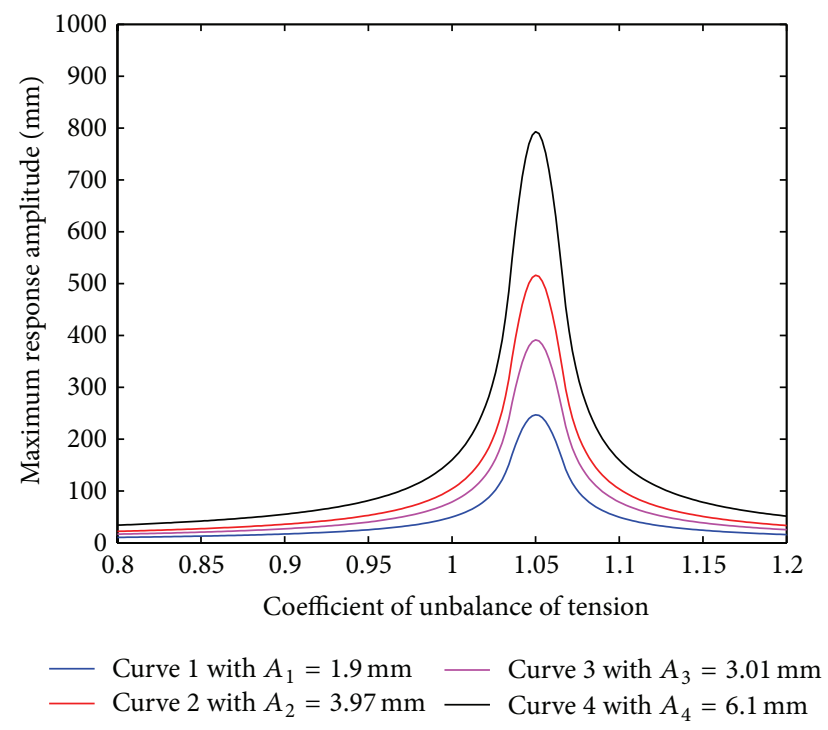

Figure 24: Amplitude response curves with varying coefficient of unbalance tension.

According to the analyses of this work, some effective measures which can be taken to reduce the large amplitude in the hoisting catenary are drawn as follows:

(1) to optimize the maximum hoisting speed to make the external excitation frequency beyond the resonance frequency range;

(2) to repair or replace the head sheave to make the axial displacements remain at a normal level;

(3) to repair or replace the tension equilibrator to realize the balanced tensions;

(4) to optimize the mass of the hoisting skip, such as adding balancing weight to change the resonance frequency.

Eventually, this investigation will provide great theoretical basis to realize resonance avoidance in the hoisting catenaries in colliery. Furthermore, the research results will also be a great help during the design phrase of the machine.

\section{Conflict of Interests}

The authors declare that there is no conflict of interests regarding the publication of this paper.

\section{Acknowledgments}

The authors would like to thank anonymous reviewers for their constructive comments and thoughtful suggestions. The authors gratefully acknowledge the support of a Project Funded by the Priority Academic Program Development of Jiangsu Higher Education Institutions (PAPD).

\section{References}

[1] D. Wang, D. Zhang, and S. Ge, "Determination of fretting parameters of hoisting rope in coalmine and fretting-fatigue behavior of steel wires," Industrial Lubrication and Tribology, vol. 65, no. 6, Article ID 17095418, pp. 436-448, 2013.

[2] D. G. Wang, D. K. Zhang, Z. F. Zhang, and S. R. Ge, "Effect of various kinematic parameters of mine hoist on fretting parameters of hoisting rope and a new fretting fatigue test apparatus of steel wires," Engineering Failure Analysis, vol. 22, pp. 92-112, 2012.

[3] G. F. Gong, "Analysis of the string vibration for mine hoist," Mining Machinery, vol. 12, pp. 48-50, 1990.

[4] S. Kaczmarczyk and W. Ostachowicz, "Transient vibration phenomena in deep mine hoisting cables. Part 1. Mathematical model," Journal of Sound and Vibration, vol. 262, no. 2, pp. 219244, 2003.

[5] S. Kaczmarczyk and W. Ostachowicz, "Transient vibration phenomena in deep mine hoisting cables. Part 2: numerical simulation of the dynamic response," Journal of Sound and Vibration, vol. 262, no. 2, pp. 245-289, 2003.

[6] S. Kaczmarczyk, "The passage through resonance in a catenaryvertical cable hoisting system with slowly varying length," Journal of Sound and Vibration, vol. 208, no. 2, pp. 243-265, 1997.

[7] J. J. Wang, G. H. Cao, Z. C. Zhu, Y. D. Wang, and W. H. Peng, "Lateral response of cable-guided hoisting system with timevarying length: theoretical model and dynamics simulation verification," Proceedings of the Institution of Mechanical Engineers C: Journal of Mechanical Engineering Science, 2015.

[8] G. H. Cao, Z. C. Zhu, W. H. Peng, and X. G. Shao, "Coupled extensional-torsional vibration frequency of hoisting rope in tower-type friction drive hoist system," in Proceedings of the International Conference on Measuring Technology and Mechatronics Automation (ICMTMA '09), vol. 1, pp. 615-618, IEEE, Hunan, China, April 2009.

[9] G. H. Cao, Z. C. Zhu, W. H. Peng, and X. B. Mao, "Modeling and natural frequency characteristics of coupled vibration with varying length of hoisting rope in drum winding system," in Proceedings of the International Conference on Computing, Control and Industrial Engineering, pp. 367-370, IEEE, Wuhan, China, June 2010.

[10] R. R. Mankowski and F. J. Cox, "Response of mine hoisting cables to longitudinal shock loads," Journal of The South African Institute of Mining and Metallurgy, vol. 86, no. 2, pp. 51-60, 1986.

[11] O. A. Goroshko, "Evolution of the dynamic theory of hoist ropes," International Applied Mechanics, vol. 43, no. 1, pp. 6467, 2007.

[12] Y. J. Li, "Dynamic study and design of the multi-rope friction hoist system," Coal Engineering, vol. 9, pp. 6-9, 2003.

[13] Z. F. Li, X. M. Xiao, Z. Q. Liu, and H. Ji, "Research of hoisting rope dynamics in mine," Coal Mine Safety, vol. 10, pp. 11-14, 2007.

[14] L.-Q. Chen, "Analysis and control of transverse vibrations of axially moving strings," Applied Mechanics Reviews, vol. 58, no. 2, pp. 91-115, 2005.

[15] R. D. Swope and W. F. Ames, "Vibrations of a moving threadline," Journal of the Franklin Institute, vol. 275, no. 1, pp. 36-55, 1963.

[16] F. R. Archibald and A. G. Emslie, "The vibration of a string having a uniform motion along its length," Journal of Applied Mechanics, vol. 25, no. 3, pp. 347-348, 1958. 
[17] W. D. Zhu and Y. Chen, "Forced response of translating media with variable length and tension: application to high-speed elevators," Proceedings of the Institution of Mechanical Engineers, Part K: Journal of Multi-Body Dynamics, vol. 219, no. 1, pp. 3553, 2005.

[18] M. Pakdemirli, A. G. Ulsoy, and A. Ceranoglu, "Transverse vibration of an axially accelerating string," Journal of Sound and Vibration, vol. 169, no. 2, pp. 179-196, 1994.

[19] L.-Q. Chen, W.-J. Zhao, and J. W. Zu, "Simulations of transverse vibrations of an axially moving string: a modified difference approach," Applied Mathematics and Computation, vol. 166, no. 3, pp. 596-607, 2005. 


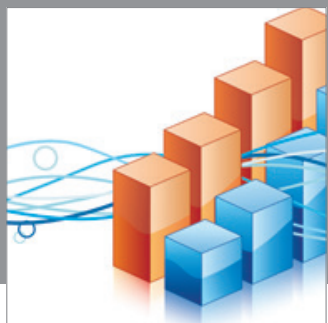

Advances in

Operations Research

mansans

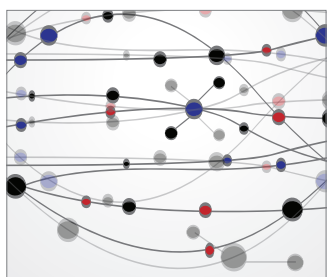

The Scientific World Journal
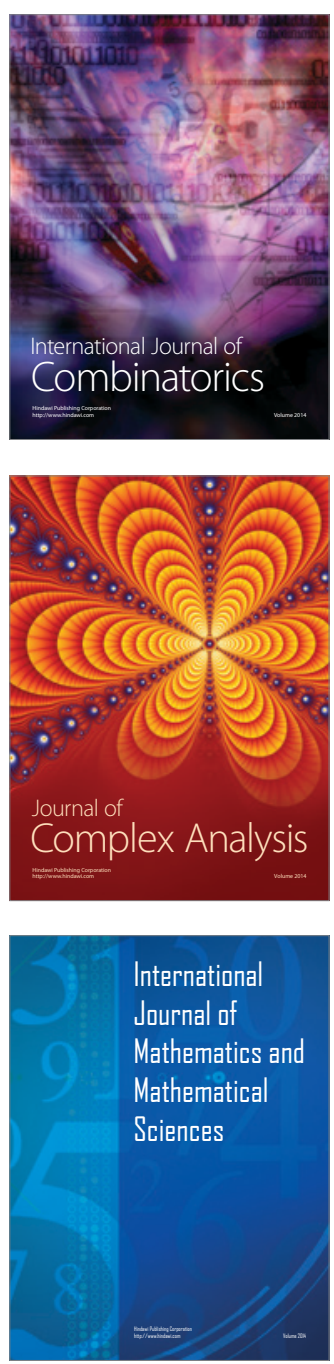
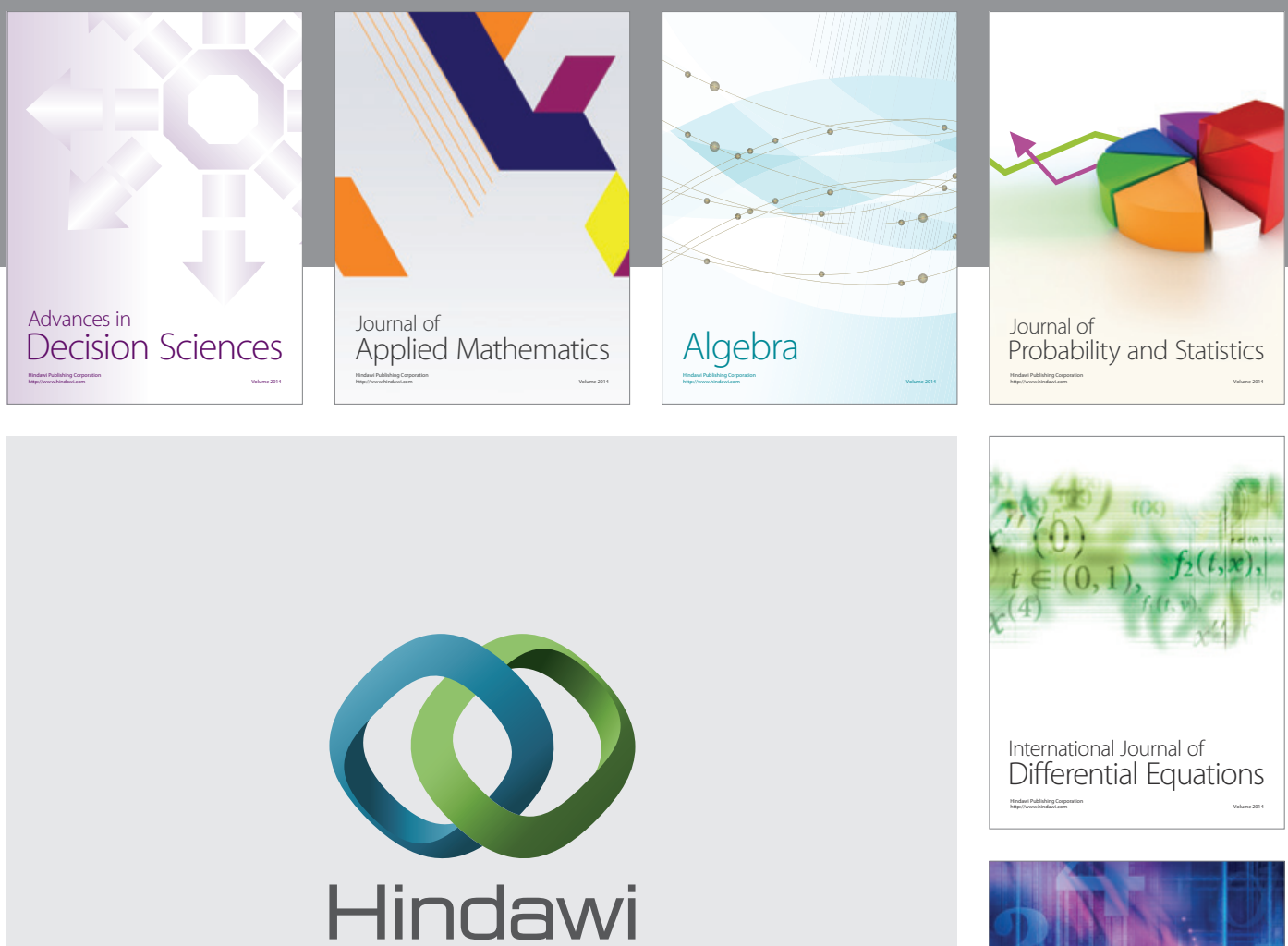

Submit your manuscripts at http://www.hindawi.com
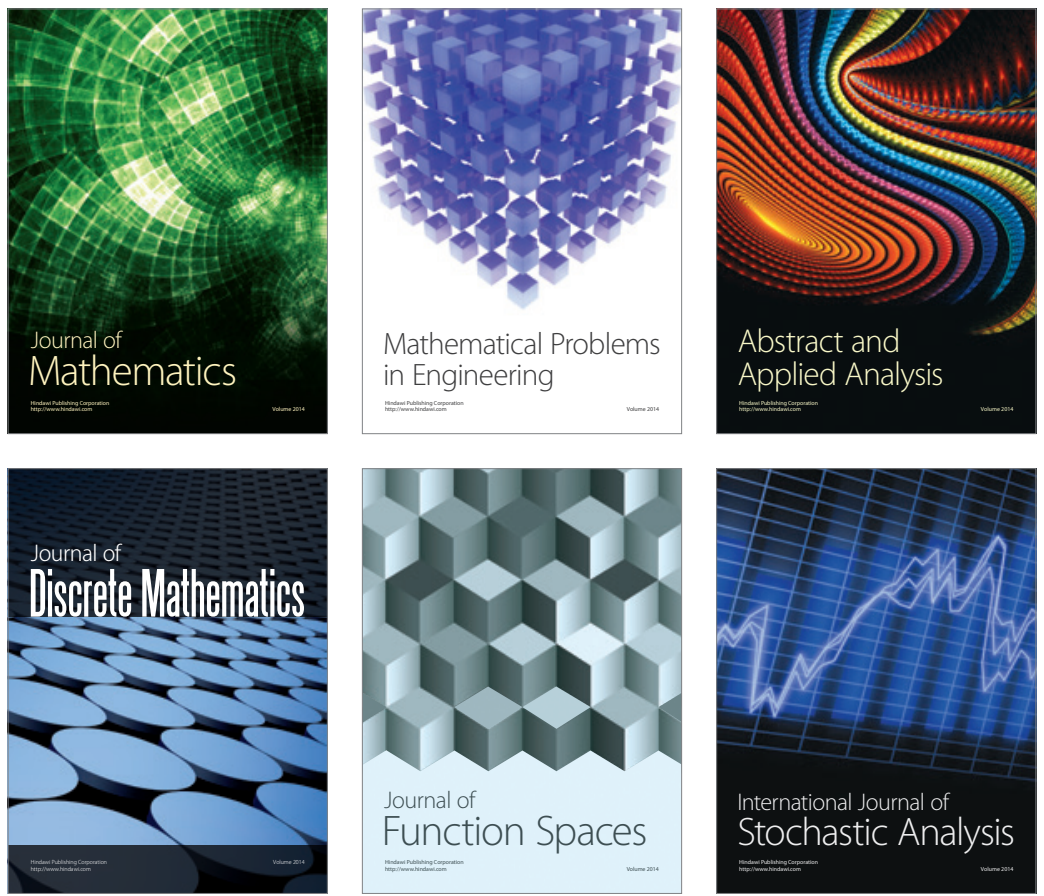

Journal of

Function Spaces

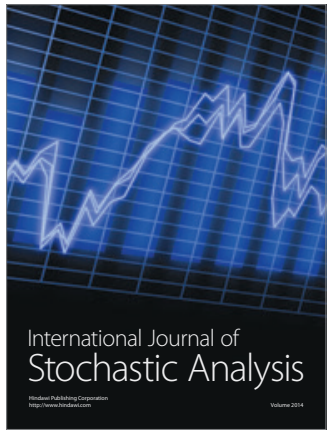

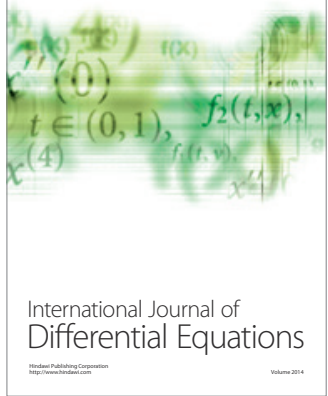
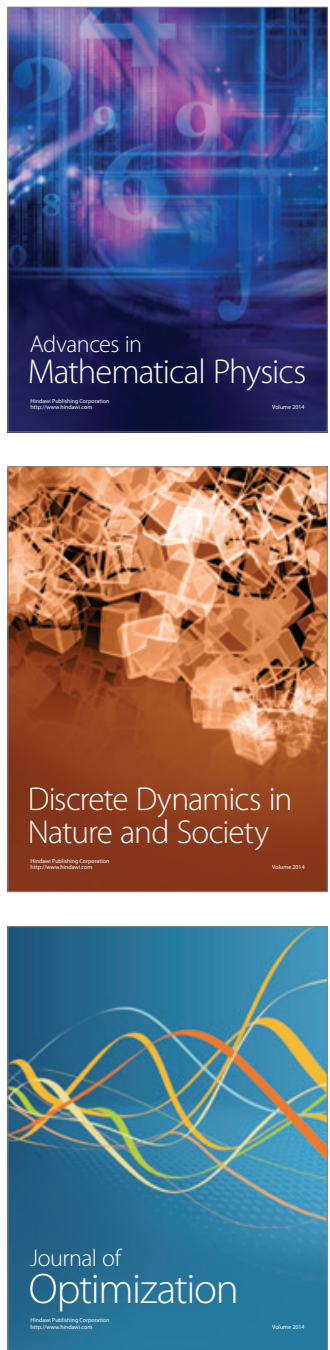